\title{
Structural and Biochemical Studies Enlighten the Unspecific Peroxygenase from Hypoxylon sp. EC38 as an Efficient Oxidative Biocatalyst
}

Laura Rotilio, Alexander Swoboda, Katharina Ebner, Claudia Rinnofner, Anton Glieder, Wolfgang Kroutil,* and Andrea Mattevi*

Cite This: ACS Catal. 2021, 11, 11511-11525

Read Online

ABSTRACT: Unspecific peroxygenases (UPOs) are glycosylated fungal enzymes that can selectively oxidize $\mathrm{C}-\mathrm{H}$ bonds. UPOs employ hydrogen peroxide as the oxygen donor and reductant. With such an easy-to-handle cosubstrate and without the need for a reducing agent, UPOs are emerging as convenient oxidative biocatalysts. Here, an unspecific peroxygenase from Hypoxylon sp. EC38 (HspUPO) was identified in an activity-based screen of six putative peroxygenase enzymes that were heterologously expressed in Pichia pastoris. The enzyme was found to tolerate selected organic solvents such as acetonitrile and acetone. HspUPO is a versatile catalyst performing various reactions, such as the

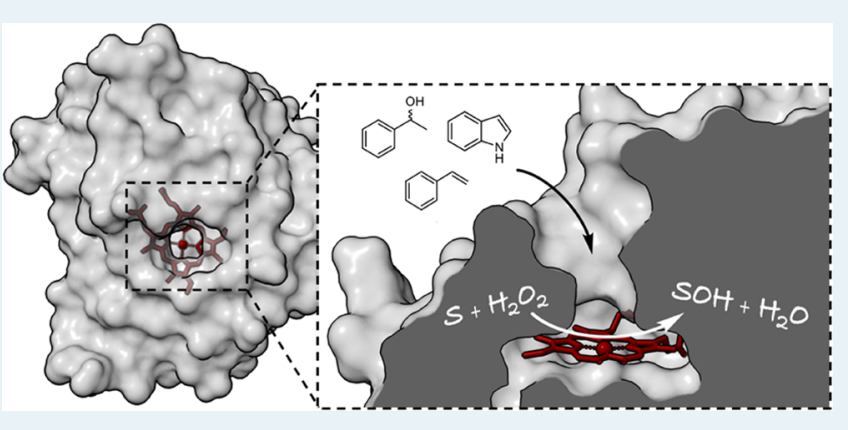
oxidation of prim- and sec-alcohols, epoxidations, and hydroxylations. Semipreparative biotransformations were demonstrated for the nonenantioselective oxidation of racemic 1-phenylethanol rac-1b (TON = 13000), giving the product with $88 \%$ isolated yield, and the oxidation of indole $\mathbf{6} \mathbf{a}$ to give indigo $\mathbf{6 b}(\mathrm{TON}=2800)$ with $98 \%$ isolated yield. Hsp UPO features a compact and rigid three-dimensional conformation that wraps around the heme and defines a funnel-shaped tunnel that leads to the heme iron from the protein surface. The tunnel extends along a distance of about $12 \AA$ with a fairly constant diameter in its innermost segment. Its surface comprises both hydrophobic and hydrophilic groups for dealing with substrates of variable polarities. The structural investigation of several protein-ligand complexes revealed that the active site of HspUPO is accessible to molecules of varying bulkiness with minimal or no conformational changes, explaining the relatively broad substrate scope of the enzyme. With its convenient expression system, robust operational properties, relatively small size, well-defined structural features, and diverse reaction scope, $H s p \mathrm{UPO}$ is an exploitable candidate for peroxygenase-based biocatalysis.

KEYWORDS: substrate recognition, protein tunnels, biocatalytic oxidation, monooxygenase, peroxygenase

\section{INTRODUCTION}

The $\mathrm{C}-\mathrm{H}$ bond is relatively inert, and its oxidation is one of the most challenging conversions in chemistry. ${ }^{1-5}$ The cytochrome P450s have been historically considered as a particularly attractive group of enzymes to perform oxidative reactions targeting $\mathrm{C}-\mathrm{H}$ groups. ${ }^{6}$ Their reaction mechanism relies on the reductive activation of molecular oxygen through a stepwise catalytic cycle that involves the formation of the highly oxidized and reactive oxoferryl intermediate (Scheme 1). ${ }^{7}$ The direct interaction between this so-called compound I and the substrate affords substrate oxygenation. Cytochrome P450s require a reducing agent, such as $\mathrm{NAD}(\mathrm{P}) \mathrm{H}$, and auxiliary flavoproteins that respectively donate and transport electrons. ${ }^{8}$ The mandatory presence of this complex protein machinery makes cytochrome $\mathrm{P} 450$ s prone to the "oxygen dilemma": the complexity of the electron-transport mediators inevitable promotes uncoupling pathways that waste reducing equivalents and significantly lower the catalytic turnover. ${ }^{9}$ These limitations, summed to the low operational stability as purified proteins, hampered the use of cytochrome P450s as general catalysts for large-scale biocatalytic applications. Several solutions have been proposed to overcome these issues. ${ }^{10}$ They include various strategies such as the usage of whole microbial cells, ${ }^{11}$ the regeneration of the reduced nicotinamide cofactor, the coexpression with NADPH-regenerating systems, ${ }^{12,13}$ and the exploitation of engineered cytochrome P450s endowed with peroxygenase activities. $^{14-18}$

In 2004, Ullrich et al. documented the discovery of a new secreted enzyme from the fungus Agrocybe aegerita. ${ }^{19}$ After its

Received: July 8, 2021

Revised: August 6, 2021

Published: September 2, 2021
प्रCatalysis 
Scheme 1. Comparison between the Mechanisms of Cytochrome P450s and UPOs

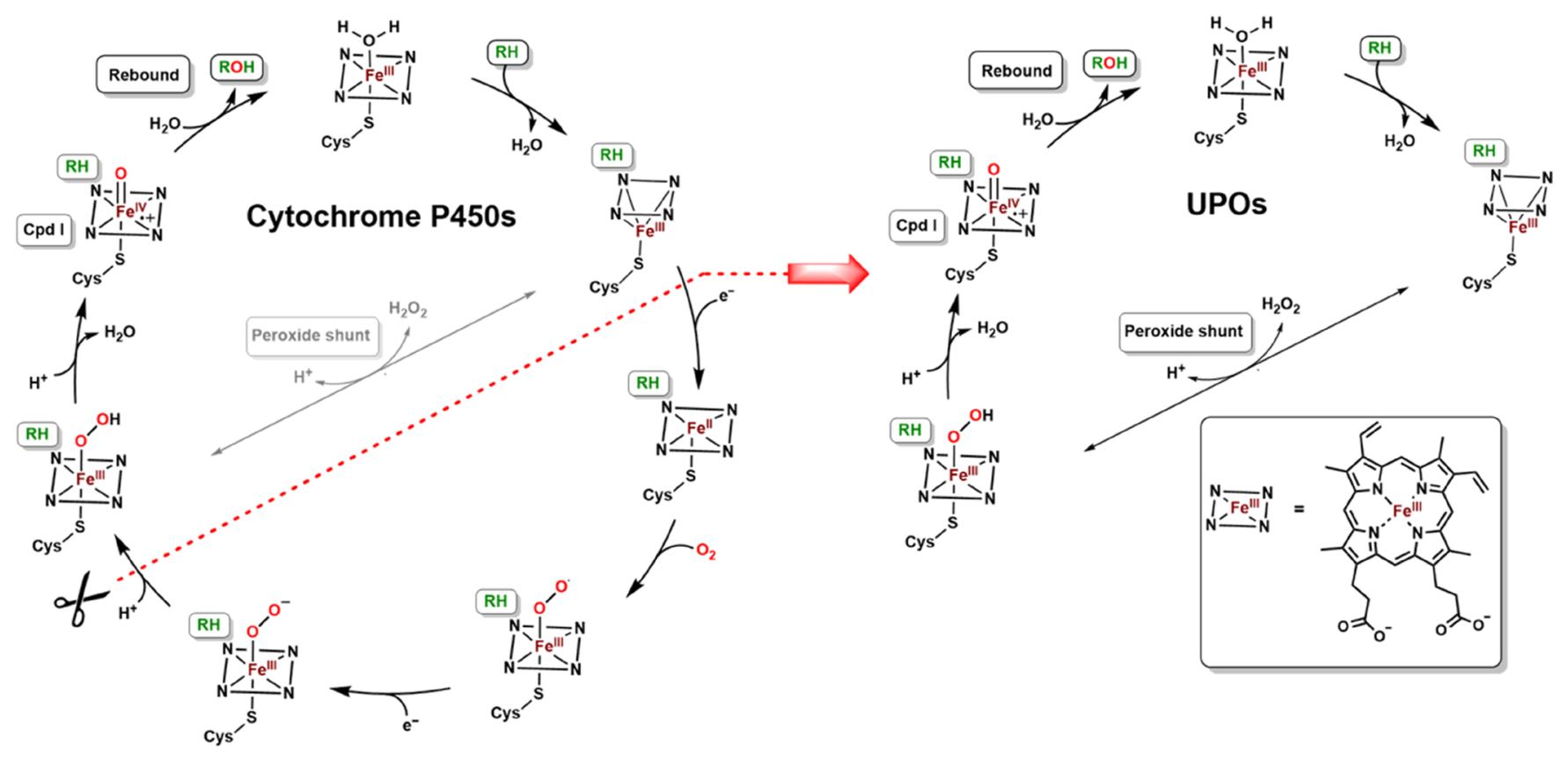

initial classification as a haloperoxidase, it was finally recognized as an unspecific peroxygenase (UPO) and considered as the first member of a new sub-subclass of oxidoreductases (E.C 1.11.2.1). ${ }^{20}$ This milestone discovery has been followed by an increasing interest in UPOs, which were defined as the "generational successors" to P450s. ${ }^{21,22}$ UPOs are highly glycosylated, naturally secreted, fungal heme-enzymes that combine a wide versatility in terms of substrate scope with a relatively simple reaction mechanism that does not need an external electron donor. ${ }^{23}$ In their reaction cycle, compound I is formed directly from the reaction between $\mathrm{H}_{2} \mathrm{O}_{2}$ and the protoporphyrin IX in the enzyme core (Scheme 1). ${ }^{24}$ The remarkable feature of this reaction is the dual function of the $\mathrm{H}_{2} \mathrm{O}_{2}$ cosubstrate, acting as both an oxygen donor and reductant that directly reacts with the enzyme prosthetic group.

To date, just the crystal structures of two peroxygenases are available, namely, one from $A$. aegerita (PDB: 2YOR for wildtype and 5OXU for the PaDa-I secretion variant $)^{25,26}$ and another from Marasmius rotula (PDB: 5FUK; unpublished). Both crystal structures highlighted and elucidated the distinctive features of UPOs whose core is mainly composed of $\alpha$-helices that organize the active site around the heme's iron center. The active site is mainly cladded with aromatic residues, conferring a preference for mildly hydrophobic substrates. UPOs have been demonstrated to be active as oxygenases on many compounds, ranging from the aliphatic propane ${ }^{27}$ and fatty acids ${ }^{28}$ to the aromatic naphthalene, ${ }^{29-31}$ benzene, ${ }^{32,33}$ phenethylamine, ${ }^{21}$ and styrene. ${ }^{34}$ A number of strategies have been described to improve the challenging expression of these enzymes. ${ }^{35-39} \mathrm{We}$ identified a highly promising novel unspecific peroxygenase from Hypoxylon sp. EC38 (HspUPO). The enzyme can efficiently be expressed as a secreted recombinant protein in $P$. pastoris and retains the activity under moderately harsh conditions. Moreover, HspUPO performs various types of reactions including hydroxylation, epoxidation, and alcohol oxidation. Additionally, we were able to successfully crystallize $H s p \mathrm{UPO}$ in the presence of different ligands, highlighting a rigid scaffold embedding a funnel for substrate diffusion to the heme.

\section{EXPERIMENTAL SECTION}

Strain Generation. Plasmids were obtained from bisy (bisy $\mathrm{GmbH}$, Hofstaehen, Austria) and generated as described in ref 40. These vectors are optimized to drive the expression of the full-length protein fused with the Mating-Factor signal sequence [MKSLSFSLALGFGSTLVYS], allowing the secretion of the target polypeptide under the control of a bidirectional promoter $P_{\mathrm{PDF}}$. The plasmids were transformed in Pichia pastoris, strain BSYBG11 (bisy GmbH, Hofstaehen, Austria), to afford the integration of the target cassette into the recipient genome by homologous recombination.

Small-Scale Protein Expression. Single colonies of the transformed P. pastoris cells, grown on YPD agar (1\% yeast extract; $2 \%$ peptone; $2 \%$ dextrose; $2 \%$ agar) and selected with Zeocin (final $100 \mu \mathrm{g} / \mathrm{mL}$ ), were picked, inoculated in $45 \mathrm{~mL}$ of buffered minimal dextrose medium (100 mM potassium phosphate $\mathrm{pH} 6 ; 1.34 \% \mathrm{YNB} ; 4 \times 10^{-5} \%$ biotin; $1 \%$ dextrose), and incubated at $28{ }^{\circ} \mathrm{C}$ with $200 \mathrm{rpm}$ shaking for $60 \mathrm{~h}$. The induction was then started by the addition of $5 \mathrm{~mL}$ of buffered minimal methanol medium (100 mM potassium phosphate $\mathrm{pH}$ 6; $1.34 \% \mathrm{YNB} ; 4 \times 10^{-5} \%$ biotin; $0,5 \%$ methanol). After 12,24 , and $36 \mathrm{~h}, 0.5 \mathrm{~mL}$ of pure methanol was added to the culture media. After a total of $180 \mathrm{~h}$ of cultivation, the cell cultures were centrifuged for $15 \mathrm{~min}$ at $8000 \mathrm{rpm}$.

Activity-Based Screenings. The cell-free supernatant containing the secreted enzymes was screened for activity using two assays.

2,2'-Azino-bis(3-ethylbenzothiazoline-6-sulfonic Acid) Diammonium Salt (ABTS) Assay. The assay mix solution consisted of $1 \mathrm{~mL}$ of $20 \times$ ABTS (440 mg of ABTS dissolved in $50 \mathrm{~mL}$ of $50 \mathrm{mM}$ sodium acetate $\mathrm{pH} 4.5)$ and $19 \mathrm{~mL}$ of 200 $\mathrm{mM}$ sodium citrate $\mathrm{pH} 4.5$. In the 96-well plate (Greiner), $15 \mu \mathrm{L}$ of the cell-free supernatant was mixed with $140 \mu \mathrm{L}$ of the assay solution and the reaction was started upon the addition of 1.75 $\mu \mathrm{L}$ of $30 \% \mathrm{H}_{2} \mathrm{O}_{2}$ in each well. Product formation was monitored following the increase in absorbance at $405 \mathrm{~nm}\left(\varepsilon_{405}=36000\right.$ $\mathrm{M}^{-1} \mathrm{~cm}^{-1}$ ) for $15 \mathrm{~min}$. 
Naphthalene Assay. The assay mix solution consisted of 2 $\mathrm{mL}$ of naphthalene $(4 \mathrm{mM}$, stock solution prepared in pure acetone) and up to $10 \mathrm{~mL}$ with $200 \mathrm{mM}$ citrate-phosphate $\mathrm{pH} 7$. Each well contained $15 \mu \mathrm{L}$ of the cell-free supernatant and 140 $\mu \mathrm{L}$ of the assay mix. The reaction was started upon the addition of $1.75 \mu \mathrm{L}$ of $30 \% \mathrm{H}_{2} \mathrm{O}_{2}$. Product formation was detected at 310 $\mathrm{nm}\left(\varepsilon_{405}=2030 \mathrm{M}^{-1} \mathrm{~cm}^{-1}\right)$.

The volumetric activities of the enzymes were calculated as follows

$$
U=\left[\left(\Delta A \Delta t^{-1} \times V_{\text {tot }} \times D\right) /\left(v_{\text {sample }} \times \varepsilon_{\text {nm }} \times d\right)\right]
$$

where $U$ is the unit per $\mathrm{mL}\left[\mu \mathrm{mol} \cdot \mathrm{mL}^{-1} \cdot \mathrm{min}^{-1}\right], V_{\text {tot }}$ is the total assay volume $[\mathrm{mL}], \Delta A \Delta t^{-1}$ is the slope $\left[\Delta A \mathrm{~min}^{-1}\right], D$ is the dilution factor of the sample, $d$ is the layer thickness $[\mathrm{cm}], v_{\text {sample }}$ is the sample volume $[\mathrm{mL}]$, and $\varepsilon_{\mathrm{nm}}$ is the extinction coefficient $\left[\mathrm{mL} \cdot \mu \mathrm{mol}^{-1} \cdot \mathrm{cm}^{-1}\right]$

Expression in Shaking Flasks. Precultures were prepared by picking a single colony and inoculating it in $5 \mathrm{~mL}$ of YPD medium ( $1 \%$ yeast extract, $2 \%$ peptone, $2 \%$ dextrose) supplemented with Zeocin $(100 \mu \mathrm{g} / \mathrm{mL}$ final $)$ followed by an overnight incubation at $28{ }^{\circ} \mathrm{C}$ with $200 \mathrm{rpm}$ shaking. After the initial growth, the preculture was split and $2.5 \mathrm{~mL}$ was added to $450 \mathrm{~mL}$ of buffered minimal dextrose medium and grown at 28 ${ }^{\circ} \mathrm{C}, 200 \mathrm{rpm}$ shaking for $72 \mathrm{~h}$. The induction was started with the addition of $50 \mathrm{~mL}$ of buffered minimal methanol medium, and every $12 \mathrm{~h}$, for a total of $72 \mathrm{~h}, 5 \mathrm{~mL}$ of pure methanol was supplemented to the culture. The culture was then harvested by centrifugation at $8000 \mathrm{rpm}$ for $15 \mathrm{~min}$, and the resulting decanted supernatant was sterile-filtrated prior to the test enzymatic activity as described in the previous paragraph.

Fermentation and Purification. HspUPO was expressed in P. pastoris using a $5 \mathrm{~L}$ glass vessel fermenter (Bioflo 3000) filled with basal salts medium $(26.7 \mathrm{~mL} / \mathrm{L} 85 \%$ phosphoric acid, $0.93 \mathrm{~g} / \mathrm{L} \mathrm{CaSO} \cdot 2 \mathrm{H}_{2} \mathrm{O}, 14.9 \mathrm{~g} / \mathrm{L} \mathrm{MgSO}_{4} \cdot 7 \mathrm{H}_{2} \mathrm{O}, 18.2 \mathrm{~g} / \mathrm{L}$ $\mathrm{K}_{2} \mathrm{SO}_{4}, 4.13 \mathrm{~g} / \mathrm{L} \mathrm{KOH} ; 40 \mathrm{~g} / \mathrm{L}$ glycerol, initial volume: $3 \mathrm{~L}$ ) supplemented with $4.35 \mathrm{~mL} / \mathrm{L}$ PTM1 trace salts and $4 \times 10^{-5} \%$ biotin. The $\mathrm{pH}$ was set to 5.0 and kept constant with ammonium hydroxide solution (30\%). The temperature was set to $28{ }^{\circ} \mathrm{C}$. The fermentation batch phase was started by inoculating $0.2 \mathrm{~L}$ of $P$. pastoris preculture and grown for $16 \mathrm{~h}$ in a baffled flask on YPD medium at $200 \mathrm{rpm}$ shaking and $28{ }^{\circ} \mathrm{C}$. After $12 \mathrm{~h}$, the glycerol in the basal salt medium was totally consumed, leading to a drop in the dissolved oxygen concentration, which was always kept above $30 \%$. At this stage, the culture was supplemented with $50 \%(\mathrm{w} / \mathrm{v})$ glycerol-feed containing 12 $\mathrm{mL} / \mathrm{L}$ PTM1 trace salts and $4 \times 10^{-5} \%$ biotin, until the cell density was $180 \mathrm{~g} / \mathrm{L}$. Methanol feed $(0.5 \% \mathrm{v} / \mathrm{v}$ final concentration) was started at the end of the glycerol fed-batch phase, when the dissolved oxygen concentration spiked at $80 \%$, and lasted for $72 \mathrm{~h}$. At the end of the fermentation, the cell culture was clarified by centrifugation at $70000 \mathrm{~g}$ for $20 \mathrm{~min}$ and the obtained supernatant was then decanted and filtrated with $0.22 \mu \mathrm{m}$ filters (Millipore). Using a cross-flow device (Sartorius), as a final downstream process, the supernatant was then concentrated 6-fold, buffer-exchanged to $10 \mathrm{mM}$ potassium phosphate $\mathrm{pH} 6$, and stored at $-20^{\circ} \mathrm{C}$. The polished supernatant was dialyzed overnight against $50 \mathrm{mM}$ Tris $-\mathrm{HCl}$ $\mathrm{pH} 7.8$ (buffer A) using a $10 \mathrm{kDa}$ dialysis cassette (Thermofisher). The day after, it was loaded by Akta System (Cytiva) equipped with a multiwavelength detector (set at 280/350/420 $\mathrm{nm}$ ) into a CaptoQ column (Cytiva) pre-equilibrated with buffer A. After washing (five column volumes) with buffer A, a linear ascending salt gradient $(0-50 \% 1 \mathrm{M} \mathrm{NaCl})$ was applied to elute bound proteins. Fractions containing the purified proteins were analyzed by SDS PAGE, and fractions containing the enzyme with an appropriate Reinheitszahl value $\left(\mathrm{Abs}_{420} / \mathrm{Abs}_{280}\right.$; experimental value of 1.8 vs the theoretical value of 1.9 ), were pooled together. Deglycosylated HspUPO was prepared by incubatingovernight with homemade $6 \mathrm{xHis}-\mathrm{EndoH}$ deglycosylase $(5 \mathrm{mg} / \mathrm{mL})$ in the ratio of 3:1 (mgHspUPO:mgENDOH). While incubating, the protein mix was dialyzed against $50 \mathrm{mM}$ Tris $/ \mathrm{HCl}, \mathrm{pH} 7.8$, to remove the excess salt. The resulting sample was loaded on a His-Trap column ( $5 \mathrm{~mL}$, Cytiva) to remove the His-tagged ENDOH, while the protein of interest was collected in the flow-through. Glycosylated and deglycosylated enzymes were concentrated with Amicon 3K (Millipore) until an appropriate volume, and then loaded on size-exclusion HiPrep Superdex 75 16/60 (Cytiva), previously equilibrated with storage buffer $50 \mathrm{mM}$ Hepes pH 7.8 (Buffer B). Protein fractions were concentrated with Amicon $3 \mathrm{~K}$ prior to crystallization screenings.

Protein Crystallization and Structure Determination. Extensive crystallization screenings were performed with several commercial kits and using an Oryx 8 robot (Douglas instruments) in sitting drop plates (Swissci, Molecular Dimension). Crystallization droplets were prepared with a $1: 1$ volume ratio by mixing $11 \mathrm{mg} / \mathrm{mL}$ protein in $50 \mathrm{mM}$ Hepes $\mathrm{pH}$ 7.8 with the reservoir solution. Promising conditions were optimized by manually prepared sitting drop plates (Cryschem, Hampton), increasing the drop volume up to $1 \mu \mathrm{L}$. Using nylon loops (Hampton research), crystals were harvested and cryocooled in liquid nitrogen. Soaking experiments $(0.5 \mathrm{~h})$ with 1-phenylimidazole and styrene were performed in cryoprotectant solutions consisting of 20\% PEG500 MME,

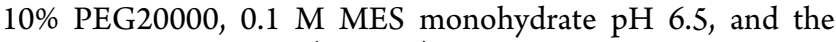
compound of interest $(15 \mathrm{mM})$, followed by flash-freezing in liquid nitrogen. X-ray diffraction data were collected at Swiss Light Synchrotron in Villigen, Switzerland (SLS), at the European Synchrotron Radiation Facility in Grenoble, France (ESRF), and at the Diamond Light Source in Didcot, United Kingdom. Diffraction images were processed with $\mathrm{XDS}^{41}$ and Aimless of the CCP4i package. ${ }^{42}$ Structure solution was performed with Molrep using 5FUK as the searching model for molecular replacement. ${ }^{43}$ Atomic models were refined with Refmac5 ${ }^{44}$ and Coot. ${ }^{45}$ Figures were created using ChimeraX. ${ }^{46}$ Superpositions were performed with DALI. ${ }^{47}$

Activities and Steady-State Kinetic Analysis. HspUPO activities were determined by absorbance-based methods using 2,2' -azino-bis(3-ethylbenzothiazoline-6-sulfonic acid) diammonium salt (ABTS), indole, 2,6-dimethoxyphenol, 5-nitro-1,3benzodioxole, 3,4-dimethoxybenzyl alcohol, and benzyl alcohol as substrates. The reactions were started by the addition of hydrogen peroxide ( $2 \mathrm{mM}$ final concentration). Prior to steadystate kinetic experiments, optimal $\mathrm{pH}$ values were determined in McIlvaine ( $\mathrm{pH} 3-8$ ) and borate saline ( $\mathrm{pH} 9$ ) buffers. Specific activities were determined by measuring the initial rates of product formation with varying substrate concentrations. The assay mixture consisted of $0.05-1.5 \mu \mathrm{M} \mathrm{HspUPO}$ and McIlvaine buffer $\mathrm{pH} 4$ (ABTS and 3,4-dimethoxybenzyl alcohol), pH 5 (2,6-dimethoxyphenol), and $\mathrm{pH} 7$ (indole, 5-nitro-1,3-benzodioxole, and benzyl alcohol). Measurements were carried out at $25{ }^{\circ} \mathrm{C}$ using a Cary100 spectrophotometer (Agilent), and product formation was followed monitoring the reactions at 405 $\mathrm{nm}$ for ABTS $\left(\varepsilon_{405}=36000 \mathrm{M}^{-1} \mathrm{~cm}^{-1}\right), 670 \mathrm{~nm}$ for indole $\left(\varepsilon_{670}\right.$ $\left.=4800 \mathrm{M}^{-1} \mathrm{~cm}^{-1}\right), 469 \mathrm{~nm}$ for 2,6-dimethoxyphenol $\left(\varepsilon_{469}=\right.$ 
$\left.27500 \mathrm{M}^{-1} \mathrm{~cm}^{-1}\right), 425 \mathrm{~nm}$ for 5-nitro-1,3-benzodioxole $\left(\varepsilon_{425}=\right.$ $\left.9700 \mathrm{M}^{-1} \mathrm{~cm}^{-1}\right), 310 \mathrm{~nm}$ for 3,4-dimethoxybenzyl alcohol $\left(\varepsilon_{310}\right.$ $\left.=9300 \mathrm{M}^{-1} \mathrm{~cm}^{-1}\right)$, and $280 \mathrm{~nm}$ for benzyl alcohol $\left(\varepsilon_{280}=1400\right.$ $\left.\mathrm{M}^{-1} \mathrm{~cm}^{-1}\right)$. Data were fit to the Michaelis-Menten equation and analyzed using GraphPad Prism software 6.0. Each point was assayed in duplicate.

Temperature and Solvent Sensitivity. HspUPO (final concentration $1 \mu \mathrm{M}$ ) was mixed with $200 \mathrm{mM}$ sodium citrate pH 4.5 (final volume $400 \mu \mathrm{L}$ ). The mix was then split in $20 \mu \mathrm{L}$ samples, and each of them was incubated, using a Thermocycler, at $35,40,50$, and $60^{\circ} \mathrm{C}$. An aliquot from each sample was tested for enzyme activity at different time points $(10,30,60$, and 90 min). The blank measurement was performed by mixing HspUPO (final concentration $50 \mathrm{~nm}$ ) and ABTS (final concentration $30 \mu \mathrm{M}$ ) in $200 \mathrm{mM}$ sodium citrate $\mathrm{pH} 4.5$, and the reaction was started upon the addition of $\mathrm{H}_{2} \mathrm{O}_{2}(2 \mathrm{mM}$ final concentration). Tolerance to solvents was assayed with the ABTS and indole as substrates in the presence of different increasing concentrations of acetone, acetonitrile, and dimethyl sulfoxide (DMSO) $(2,5,10,20$, and $30 \%)$. The mix used for the ABTS oxidation assay consisted of HspUPO (final concentration $50 \mathrm{~nm}$ ), ABTS (final concentration $30 \mu \mathrm{M}$ ), and increasing concentrations of solvent in $200 \mathrm{mM}$ sodium citrate $\mathrm{pH}$ 4.5. The mix used for the indigo production assay consisted of HspUPO (final concentration $1.5 \mu \mathrm{M}$ ), indole (final concentration $100 \mu \mathrm{M}$; stock solution solubilized in acetone or acetonitrile), and increasing concentrations of solvents in 50 $\mathrm{mM}$ potassium phosphate $\mathrm{pH}$ 7.4. The reaction was started by the addition of $\mathrm{H}_{2} \mathrm{O}_{2}(2 \mathrm{mM}$ final concentration) and was carried out at $25^{\circ} \mathrm{C}$.

The equation used to calculate the residual activity (\%) is

$$
\left(k_{\text {cat (obs) }} / k_{\text {cat (standard) }}\right) \times 100
$$

where $k_{\mathrm{cat}}$ (obs) is the $k_{\mathrm{cat}}$ calculated for each temperature/solvent percentage and $k_{\text {cat (standard) }}$ is the $k_{\text {cat }}$ calculated with the standard assay condition.

Biotransformations. Reactions on a $1 \mathrm{~mL}$ scale were carried out in crimp top glass vials ( $1.5 \mathrm{~mL}$ volume) with a septum in horizontal adjustment in a benchtop incubator at 30 ${ }^{\circ} \mathrm{C}$ and $500 \mathrm{rpm}$. The reaction mixture contained $\mathrm{Hsp} \mathrm{UPO}(7$ $\mu \mathrm{M})$ and the substrate $(1 \mathrm{a}-6 \mathrm{a}, 10 \mathrm{mM}, 50 \mu \mathrm{L}$ of a $200 \mathrm{mM}$ stock in acetonitrile, added last) in tricine buffer $100 \mathrm{mM}, \mathrm{pH}$ 7.5 with $5 \%(\mathrm{v} / \mathrm{v})$ acetonitrile. The conversion was started by the continuous addition of in total $40 \mu \mathrm{L}$ of a $0.5 \mathrm{M} \mathrm{H}_{2} \mathrm{O}_{2}$ solution in a reaction buffer $(10 \mu \mathrm{L} / \mathrm{h}$ over $4 \mathrm{~h}$ for $\mathbf{1 a}-\mathbf{5 a}, 40$ $\mu \mathrm{L} / \mathrm{h}$ over $1 \mathrm{~h}$ for $6 \mathrm{a}$, final concentration of $\mathrm{H}_{2} \mathrm{O}_{2}: 20 \mathrm{mM}, 2$ equiv) with a $\mathrm{kdScientific} \mathrm{pump,} \mathrm{equipped} \mathrm{with} 1 \mathrm{~mL}$ Omnifix-F syringes from BRAUN ( $\varnothing 4.7 \mathrm{~mm}$ ) and 100 Sterican needles ( $\varnothing$ $0.80 \mathrm{~mm} \times 120 \mathrm{~mm}$ ). After completion of $\mathrm{H}_{2} \mathrm{O}_{2}$ addition, the reaction was stopped by the addition of $2 \mu \mathrm{L}$ of catalase from $M$. lysodeikticus $(170000 \mathrm{U} / \mathrm{mL})$ and $15 \mathrm{mins}$ of incubation at 500 rpm and room temperature to quench the excess $\mathrm{H}_{2} \mathrm{O}_{2}$. Reactions containing substrates $\mathbf{1 a}, \mathbf{3} \mathbf{a}-\mathbf{5} \mathbf{a}$, and $\mathrm{rac}-\mathbf{1} \mathbf{b}$ were extracted with ethyl acetate $(2 \times 500 \mu \mathrm{L})$, dried over $\mathrm{Na}_{2} \mathrm{SO}_{4}$, and analyzed on GC. Reactions containing substrate 2 a were diluted with acetonitrile $(1 \mathrm{~mL}$, dilution factor $=2)$, thoroughly vortexed, centrifuged (14 $650 \mathrm{rpm}, 5 \mathrm{~min}$, room temperature), and filtered prior to analysis on high-performance liquid chromatography (HPLC). Reactions containing substrate 6a were directly centrifuged, which led to accumulation of the insoluble $\mathbf{6 b}$ as a pellet on the bottom of the vial. The supernatant was removed and treated as with substrate $2 \mathrm{a}$. The remaining dark-blue pellet was dried under a gentle airflow and dissolved in DMSO (dilution factor $=10$ ). The aqueous supernatant as well as the DMSO solute was analyzed individually on HPLC.

Semipreparative-Scale Biotransformations. Synthesis of 1c: The reaction was carried out on a $20 \mathrm{~mL}$ scale in a microwave vial with a septum cap in horizontal adjustment in a benchtop incubator at $30^{\circ} \mathrm{C}$ and $300 \mathrm{rpm}$. The reaction mixture contained $\mathrm{Hsp} \mathrm{UPO}\left(c_{\mathrm{final}}=7 \mu \mathrm{M}\right)$ and the substrate rac-1b $(244$ $\mathrm{mg}$, added as $2 \mathrm{~mL}$ of a $1 \mathrm{M}$ stock in acetonitrile, $c_{\text {final }}=100 \mathrm{mM}$ ) in tricine buffer $(100 \mathrm{mM}, \mathrm{pH} 7.5)$ with 10 vol \% acetonitrile. The conversion was started by the continuous addition of in total $1.6 \mathrm{~mL}$ of a $1375 \mathrm{mM} \mathrm{H} \mathrm{O}_{2}$ solution in a reaction buffer $\left(400 \mu \mathrm{L} / \mathrm{h}\right.$ over $4 \mathrm{~h}, c_{\text {final }}=110 \mathrm{mM}, 1.1$ equiv $)$ with a kdScientific pump, equipped with a $5 \mathrm{~mL}$ Omnifix-F syringe from BRAUN ( $\varnothing 10 \mathrm{~mm}$ ) and a 100 Sterican needle $(\varnothing 0.80$ $\mathrm{mm} \times 120 \mathrm{~mm})$. After completion of $\mathrm{H}_{2} \mathrm{O}_{2}$ addition, the reaction was extracted $(3 \times 20 \mathrm{~mL}$ ethyl acetate). The combined organic phases were dried over $\mathrm{Na}_{2} \mathrm{SO}_{4}$, the solvent was evaporated under reduced pressure, and the product was purified by flash chromatography (cyclohexane/ethyl acetate, 9:1). Synthesis of $\mathbf{6 b}$ : The reaction vessel and adjustment were identical to the conditions described above for $\mathbf{1 c}$. The reaction mixture contained $H s p \mathrm{UPO}\left(c_{\text {final }}=7 \mu \mathrm{M}\right)$ and indole $6 \mathrm{a}(46.8$ $\mathrm{mg}$, directly dissolved in reaction buffer, $c_{\text {final }}=20 \mathrm{mM}$ ) in tricine buffer $100 \mathrm{mM}, \mathrm{pH}$ 7.5. The conversion was started by the continuous addition of in total $0.8 \mathrm{~mL}$ of a $550 \mathrm{mM} \mathrm{H}_{2} \mathrm{O}_{2}$ solution in a reaction buffer $\left(800 \mu \mathrm{L} / \mathrm{h}\right.$ over $1 \mathrm{~h}, c_{\text {final }}=22 \mathrm{mM}$, 1.1 equiv). After completion of $\mathrm{H}_{2} \mathrm{O}_{2}$ addition, the reaction was stopped by the addition of $40 \mu \mathrm{L}$ of catalase from M. lysodeikticus $(170000 \mathrm{U} / \mathrm{mL})$ and $15 \mathrm{~min}$ of incubation at $500 \mathrm{rpm}$ at room temperature to quench the excess $\mathrm{H}_{2} \mathrm{O}_{2}$. The reaction solution was then transferred to two $15 \mathrm{~mL}$ plastic tubes and centrifuged to separate the insoluble indigo from the aqueous phase. The supernatant was removed and analyzed as stated for $1 \mathrm{~mL}$ scale biotransformations. The remaining indigo pellet was washed 3 times with deionized $\mathrm{H}_{2} \mathrm{O}$ to remove any buffer salt residues, and the wet pellet was then dried by lyophilization. The structure of both preparative-scale biotransformation products $1 \mathrm{c}$ and $\mathbf{6 b}$ was verified by NMR.

\section{RESULTS AND DISCUSSION}

Peroxygenase Candidate Screening and HspUPO Isolation. To identify an efficient and versatile UPO, six

Table 1. Screening of UPO Candidates

\begin{tabular}{|c|c|c|c|}
\hline source of origin & accession code & $\begin{array}{c}\text { sequence identity } \\
\text { (\%) with } \\
\text { AaeUPO }\end{array}$ & $\begin{array}{c}\text { relative activity } \\
\text { ABTS/ } \\
\text { naphthalene }^{b}\end{array}$ \\
\hline A. aegerita & B9W4V6 ${ }^{c}$ & 100 & $100 / 100$ \\
\hline $\begin{array}{l}\text { Aspergillus } \\
\quad \text { brasiliensis }\end{array}$ & OJJ73116.1 & 35 & $200 / 68$ \\
\hline $\begin{array}{l}\text { Hypoxylon sp. } \\
\text { EC38 } \\
\text { (HspUPO) }\end{array}$ & OTA57433.1 ${ }^{c}$ & 30 & $277 / 53$ \\
\hline $\begin{array}{l}\text { Podospora } \\
\text { anserina }\end{array}$ & $X P \_001911526.1^{c}$ & 28 & $52 / 16$ \\
\hline Daldinia sp. & OTB17553.1 ${ }^{c}$ & 30 & $22 / 17$ \\
\hline Aspergillus niger & GAQ45152 $2^{c}$ & 34 & $270 / 30$ \\
\hline A. niger & XP_001390900.2 ${ }^{d}$ & 33 & $301 / 33$ \\
\hline
\end{tabular}

${ }^{a} \mathrm{UPO}$ from A. aegerita (PDB ID: 2YOR). ${ }^{25}{ }^{b}$ Activity of $15 \mu \mathrm{L}$ of cellfree supernatant using ABTS and naphthalene, relative to the enzyme from $A$. aegerita, which is used as a reference. ${ }^{c}$ UniPROT database. ${ }^{d}$ Database at the National Center for Biotechnology Information. 

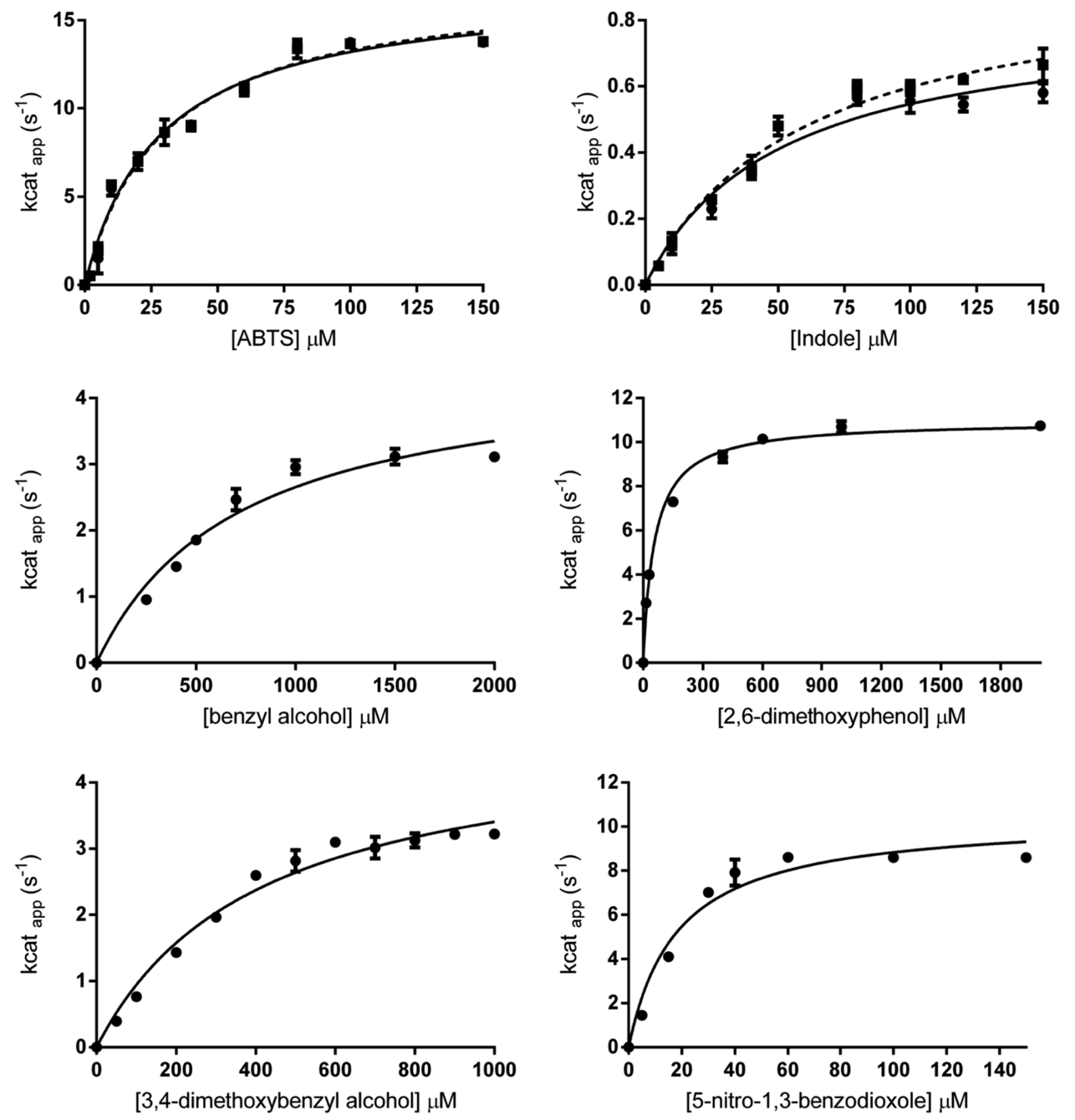

Figure 1. Biochemical characterization of HspUPO. Michaelis-Menten curves for six substrates. ABTS and indole were evaluated also using the deglycosylated HspUPO (dashed lines).

Table 2. Steady-State Kinetic Parameter

$\begin{array}{lccc}\quad \text { substrate } & k_{\text {cat }}\left(\mathrm{s}^{-1}\right) & K_{\mathrm{M}}(\mu \mathrm{M}) & k_{\text {cat }} / K_{\mathrm{M}}\left(\mathrm{s}^{-1} \mu \mathrm{M}^{-1}\right) \\ \text { ABTS } & 16.94 \pm 0.73 & 30 \pm 3.65 & 0.57 \\ \text { indole } & 0.79 \pm 0.055 & 54 \pm 8.16 & 0.015 \\ \text { benzyl alcohol } & 4.56 \pm 0.39 & 680 \pm 0.14 & 0.006 \\ \begin{array}{l}\text { 2,6- } \\ \quad \text { dimethoxyphenol }\end{array} & 11 \pm 0.17 & 57.5 \pm 5 & 0.191 \\ \begin{array}{l}\text { 3,4-dimethoxybenzyl } \\ \quad \text { alcohol }\end{array} & 7.15 \pm 0.58 & 758 \pm 100 & 0.01 \\ \begin{array}{l}\text { 5-nitro-1,3- } \\ \quad \text { benzodioxole }\end{array} & 10.4 \pm 0.55 & 18 \pm 3.42 & 0.57 \\ \end{array}$

enzyme candidates of fungal origin were tested. They were selected to represent a sufficiently diverse panel of putative peroxygenases as predicted from the similarity of their amino acid sequences to the sequence of UPO from $A$. aegerita ${ }^{25}$ (Table 1 ). The enzymes were expressed as secreted recombinant proteins using P. pastoris with satisfactory secretion levels $(0.2 \mathrm{~g} /$ $\mathrm{L})$. We probed the peroxidase and peroxygenase activities of the candidate enzymes using two potential substrates: $2,2^{\prime}$-azinobis(3-ethylbenzothiazoline-6-sulfonic acid) diammonium salt (ABTS; peroxidase assay, $\mathrm{pH} 4.5$ ) and naphthalene (peroxygenase assay, $\mathrm{pH} 7$ ). For both substrates, convenient spectrophotometric assays were employed. Although all UPO candidates exhibited activities when expressed on a $0.45 \mathrm{~L}$ scale
(Table 1), it became clear that when performing the protein expression on a $5 \mathrm{~L}$ scale, only the enzyme from Hypoxylon sp. EC38 (HspUPO) fully retained its heme cofactor when purified, while all other enzymes mostly became inactive. Thus, HspUPO emerged as the logical candidate for further biochemical and structural studies (see Figure S1 for details about the purification procedures and yields).

Steady-State Kinetics on HspUPO. In the early stages of the project, we observed that addition of indole and $\mathrm{H}_{2} \mathrm{O}_{2}$ to the secreted media immediately led to a blue color, suggesting that HspUPO converts indole to indigo. Therefore, we initially chose indole to study the steady-state kinetics of a reaction that involves substrate oxygenation (peroxygenase activity). We further used ABTS to probe a substrate-oxidation reaction (peroxidase activity). HspUPO oxidizes efficiently ABTS $\left(k_{\text {cat }}=\right.$ $\left.16.94 \mathrm{~s}^{-1}\right)$, whereas a slower, yet pronounced, catalytic turnover was observed for indole $\left(k_{\text {cat }}=0.79 \mathrm{~s}^{-1}\right)$. Both ABTS and indole exhibited remarkably low $K_{\mathrm{M}}$ values of $\sim 30-50 \mu \mathrm{M}$ so that their activities reached the plateau at about $150 \mu \mathrm{M}$ concentrations (Figure 1 and Table 2). Based on these initial promising observations, we expanded our analysis to other potential substrates: benzyl alcohol, 2,6-dimethoxyphenol, 3,4-dimethoxybenzyl alcohol, and 5-nitro-1,3-benzodioxole. ${ }^{35}$ For all of these compounds, we observed good activities with $k_{\text {cat }}$ values in the 

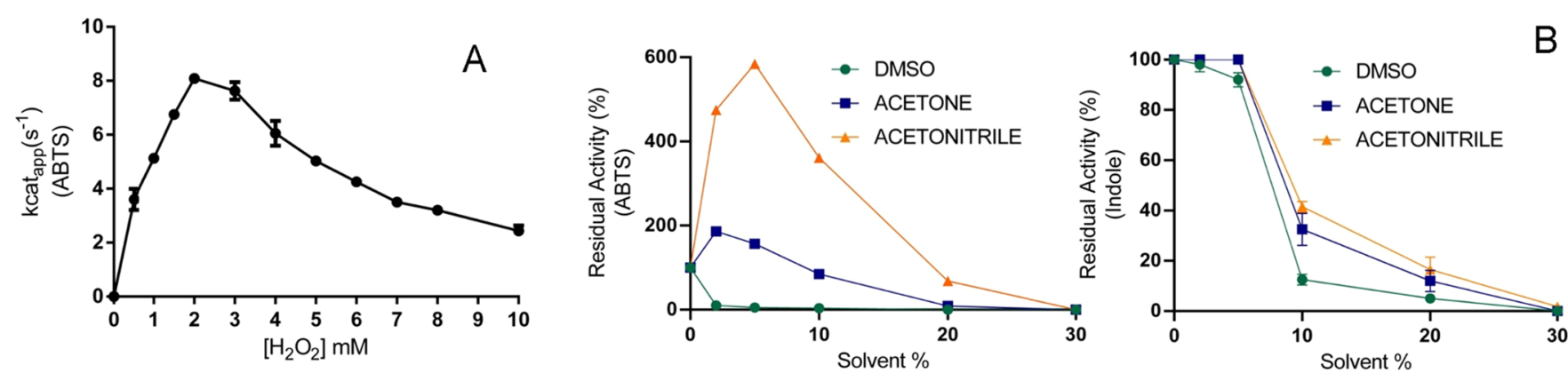

Figure 2. Conditions for $H s p$ UPO optimal activity. (A) To probe the sensitivity toward hydrogen peroxide, the assay mixtures consisted of $200 \mathrm{mM}$ sodium citrate $\mathrm{pH} 4.5,30 \mu \mathrm{M}$ ABTS, $50 \mathrm{nM}$ HspUPO, and increasing concentrations of $\mathrm{H}_{2} \mathrm{O}_{2}$. (B) Solvent tolerance was probed in reaction mixtures consisting of $200 \mathrm{mM}$ sodium citrate $\mathrm{pH} 4.5,2 \mathrm{mM} \mathrm{H}_{2} \mathrm{O}_{2}, 30 \mu \mathrm{M}$ ABTS, and $50 \mathrm{nM} \mathrm{HspUPO}$. In the experiments performed with indole, the reaction mixture consisted of $50 \mathrm{mM}$ potassium phosphate $\mathrm{pH} 7.4,2 \mathrm{mM} \mathrm{H}_{2} \mathrm{O}_{2}, 100 \mu \mathrm{M}$ indole, and $1.5 \mu \mathrm{M} \mathrm{HspUPO}$. Each data point represents the mean and standard deviation from two measurements.
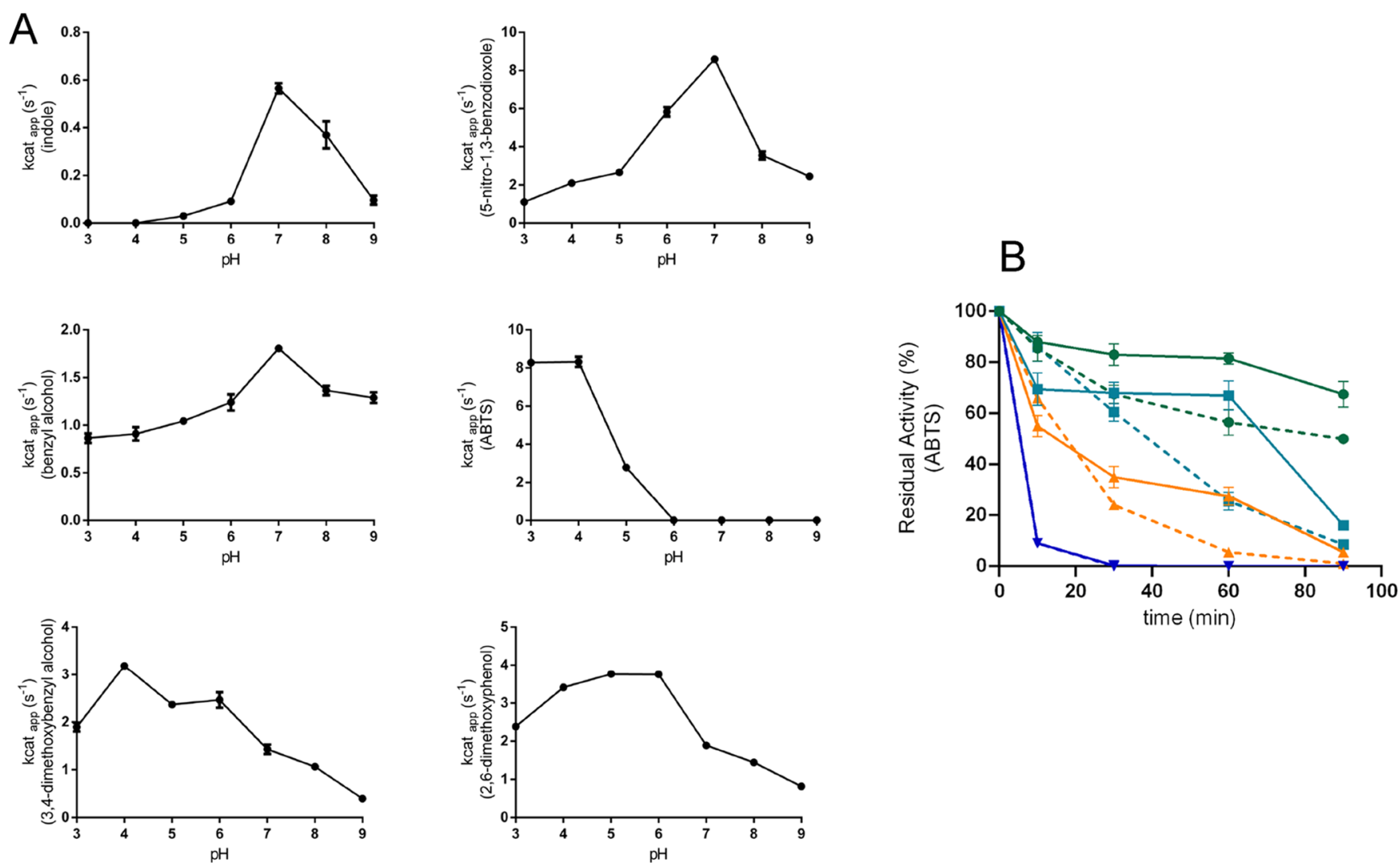

Figure 3. $\mathrm{pH}$ activity profiles and thermal inactivation assay on purified $H s p \mathrm{UPO}(\mathrm{A}) \mathrm{pH}$ activity profiles. (B) Thermal inactivation was evaluated using glycosylated (solid lines) and deglycosylated (dashed lines) $\mathrm{HspUPO}$ with $\mathrm{ABTS}$ as the substrate (blue, $60^{\circ} \mathrm{C}$; orange, $50^{\circ} \mathrm{C}$; cyan, $40^{\circ} \mathrm{C}$; green, $\left.35^{\circ} \mathrm{C}\right)$.

range of $3-12 \mathrm{~s}^{-1}$ (Table 2 and Figure 1). In summary, HspUPO proved to be active on several diverse substrates.

Operational Robustness of HspUPO. Besides the advantage of bypassing the need for expensive and demanding electron donors, the $\mathrm{H}_{2} \mathrm{O}_{2}$ cosubstrate may come at a price: the potential oxidative damage inflicted to the protein and reactants used in the biotransformations. Therefore, we probed the capacity of HspUPO to withstand relatively high hydrogen peroxide concentrations for prolonged incubation times. We conducted these experiments employing HspUPO with ABTS as the substrate (Figure 2A). Rewardingly, the enzyme retained 75 and $40 \%$ of the activity in the presence of $5 \mathrm{mM}$ and $10 \mathrm{mM}$ $\mathrm{H}_{2} \mathrm{O}_{2}$, whereas the optimal activity was observed at $2 \mathrm{mM} \mathrm{H}_{2} \mathrm{O}_{2}$ $\left(k_{\text {cat }} \sim 8 \mathrm{~s}^{-1}\right)$. A similar pattern was reported for UPO from $A$. aegerita. ${ }^{19}$ Our data on the Hypoxylon sp. enzyme thereby confirm that UPOs are not severely affected by elevated hydrogen peroxide concentrations as needed for efficient biotransformations.

Hydrophobic substrates require a range of solvents for improving substrate availability in the aqueous phase. Thus, the solvent tolerance of native $H s p \mathrm{UPO}$ was assessed toward several commonly used solvents: DMSO, acetone, and acetonitrile. DMSO was hardly tolerated by Hsp UPO when assayed with $\mathrm{ABTS}$ as the substrate. Indeed, the residual activity dropped to near $0 \%$ already with $2 \%(\mathrm{v} / \mathrm{v})$ DMSO (Figure $2 \mathrm{~B}$, green solid line). To provide additional validation to this finding, we 
Table 3. Biocatalytic Oxidation of Various Chemical Functionalities with Purified HspUPO

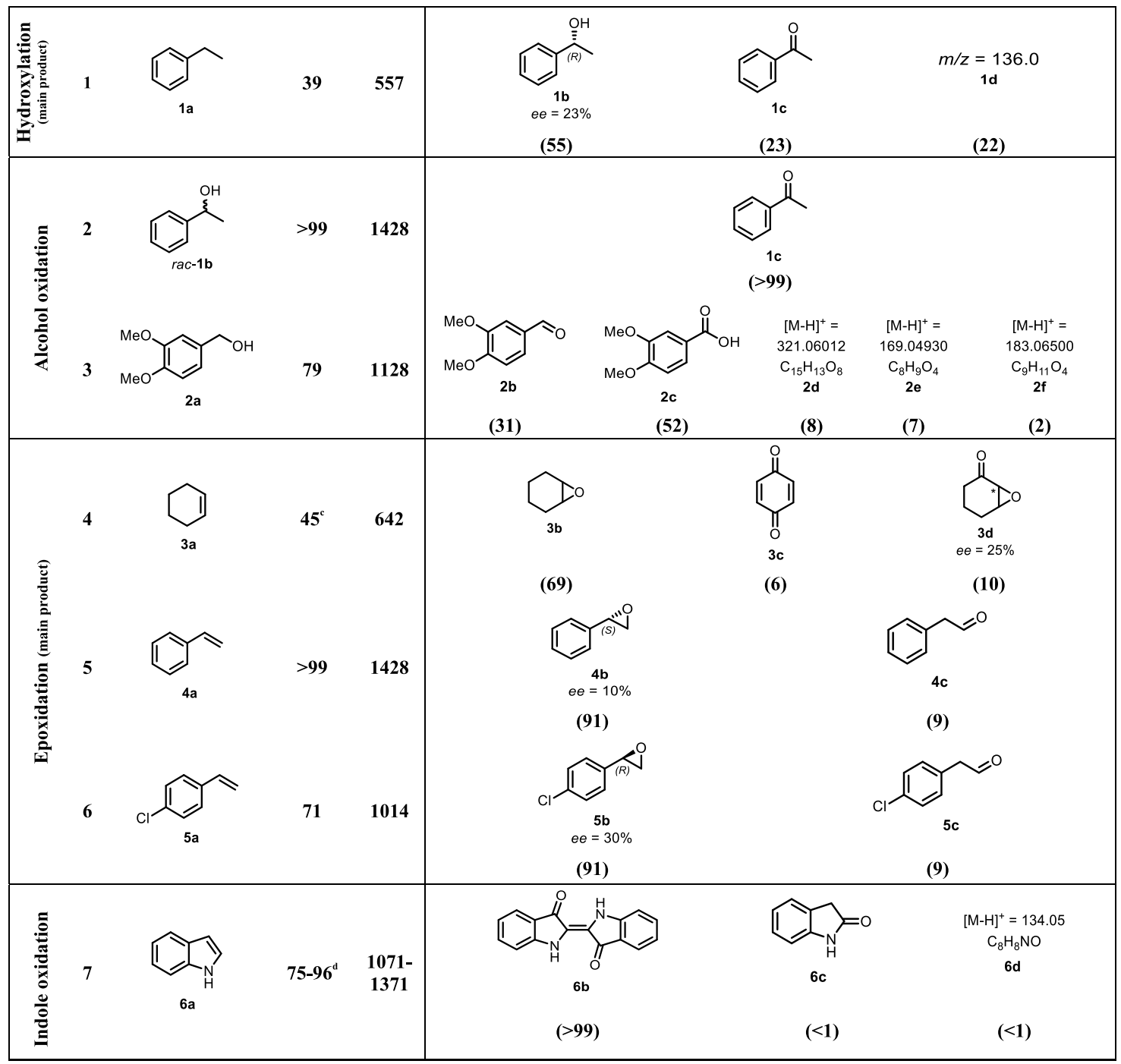

${ }^{a}$ Conversions are based on substrate recovery with the exception of $1 \mathbf{a}$ and $3 \mathbf{a}$, where the conversions are based on product formation due to volatility of the substrate. Reaction conditions are as follows: substrate $10 \mathrm{mM}$, acetonitrile $5 \%, \mathrm{HspUPO} 7 \mu \mathrm{M}, \mathrm{H}_{2} \mathrm{O}_{2} 20 \mathrm{mM}(2$ equiv, continuous addition), tricine buffer $100 \mathrm{mM} \mathrm{pH} \mathrm{7.5,} V_{\text {final }}=1 \mathrm{~mL}, 30{ }^{\circ} \mathrm{C}, 500 \mathrm{rpm}, 4 \mathrm{~h}(1 \mathrm{~h} \mathrm{for} 6 \mathrm{a})$. All experiments were performed in triplicates. ${ }^{b}$ Product ratio is determined by the peak area or calibration with the commercial reference material on GC or HPLC. ${ }^{c}$ For analysis of trace oxidation products (missing $15 \%$ in the product ratio), see the Supporting Information. ${ }^{d}$ Conversion is displayed as a range since replicates deviate more than $10 \%$.

investigated the impact of DMSO on indole conversion (Figure $2 \mathrm{~B}$, green solid line). With this substrate, the tolerance to DMSO was slightly better as compared to the activity loss registered for ABTS. As observed for other peroxygenases (i.e., A. aegerita UPO), DMSO appears to be an inhibitor of HspUPO, likely by binding to the iron center. ${ }^{26}$ In general, the activity was retained as long as the DMSO percentage was no higher than $5 \%$.

On the other hand, acetone and acetonitrile boosted the activity of HspUPO toward ABTS by up to twofold (2\% acetone) and sixfold (5\% acetonitrile), respectively (Figure $2 \mathrm{~B}$ ). We speculate that the less polar acetone and acetonitrile cosolvents facilitate binding of the charged ABTS and thereby accelerate its conversion. Likewise, indole conversions were significantly affected by acetone and acetonitrile only at cosolvent concentrations above 10\% (>50\% decrease; Figure 2B). In summary, both acetone and acetonitrile may be applied at $10-20 \%$ concentrations without exceedingly large decreases in the enzymatic activities.
In addition to the sensitivity to the chemicals employed in bioconversions, critical factors are the $\mathrm{pH}$ and temperature. We found that HspUPO is optimally active at neutral $\mathrm{pH}$ with indole, 5-nitro-1,3-benzodioxole, and benzyl alcohol, whereas more acidic $\mathrm{pH}$ values are optimal for the conversions of ABTS ( $\mathrm{pH} 4)$, 3,4-dimethoxybenzyl alcohol ( $\mathrm{pH} 4)$, and 2,6dimethoxyphenol ( $\mathrm{pH}$ 5) (Figure 3A). Such pronounced variations in the $\mathrm{pH}$ dependency have been observed before for other peroxidases and peroxygenases. ${ }^{35}$ We further probed the operational robustness of $H s p \mathrm{UPO}$ by measuring the activity toward ABTS after incubation at increasing temperatures (Figure 3B). HspUPO was mostly inactivated after 20-30 min exposures to temperatures higher than $50{ }^{\circ} \mathrm{C}$. Conversely, the overall activity of $H s p$ UPO was minimally affected at $40^{\circ} \mathrm{C}$, and only after $90 \mathrm{~min}$, the enzyme mostly lost activity. At the temperature of $35^{\circ} \mathrm{C}$, there was some activity loss only after 60 min, but the enzyme remained mostly active even after longer incubations. 
Table 4. Crystallographic Statistics

\begin{tabular}{|c|c|c|c|c|c|}
\hline HspUPO complex & imidazole (7O1R) & 1-phenylimidazole (7O1X) & S-1,2-propandiol (7O1Z) & MES (7O2D) & styrene $(7 \mathrm{O} 2 \mathrm{G})$ \\
\hline resolution range & $48.2-1.3$ & $48.0-1.6$ & $48.0-1.8$ & $29.8-2.6$ & $52.6-2.1$ \\
\hline space group & $P 4_{1} 2_{1} 2$ & $P 4_{1} 2_{1} 2$ & $P 4_{1} 2_{1} 2$ & $P 4_{1} 2_{1} 2$ & $P 4_{1} 2_{1} 2$ \\
\hline unit cell axes $(\AA)$ & 71.771 .7153 .7 & 71.571 .5153 .2 & 71.471 .4152 .6 & 73.173 .1154 .1 & 71.971 .9154 .5 \\
\hline total reflections ${ }^{a}$ & $2556180(120423)$ & $687067(35537)$ & 478559 (28 188) & $325802(42673)$ & $302461(26523)$ \\
\hline unique reflections $^{a}$ & $99264(4837)$ & $53428(2629)$ & $37610(2196)$ & $12383(1603)$ & $23855(1968)$ \\
\hline multiplicity $^{a}$ & $25.8(25.0)$ & $12.9(13.5)$ & $12.8(12.7)$ & $26.3(26.6)$ & $12.7(13.5)$ \\
\hline completeness $^{a}(\%)$ & $99.96(99.85)$ & $99.96(99.98)$ & $99.99(100.00)$ & $99.8(99.3)$ & $97.1(99.8)$ \\
\hline mean $I / \sigma(I)^{a}$ & $14.8(0.8)$ & $11.5(2.1)$ & $25.7(5.8)$ & $22.5(4.7)$ & $8.0(0.5)$ \\
\hline Wilson $B$-factor & 14.83 & 19.51 & 22.77 & 52.54 & 49.00 \\
\hline$R$-merge $e^{a, b}$ & $0.155(4.6)$ & $0.159(1.7)$ & $0.059(0.40)$ & $0.13(0.91)$ & $0.21(5.42)$ \\
\hline $\mathrm{CC} 1 / 2^{a, c}$ & $0.999(0.44)$ & $0.999(0.812)$ & $1.0(0.963)$ & $0.999(0.991)$ & $0.998(0.379)$ \\
\hline reflections used in refinement ${ }^{a}$ & $99151(9737)$ & $53337(5238)$ & $37532(3665)$ & $12383(1183)$ & $23783(2365)$ \\
\hline$R$-work ${ }^{a}$ & $0.140(0.309)$ & $0.134(0.181)$ & $0.123(0.151)$ & $0.200(0.191)$ & $0.202(0.413)$ \\
\hline$R$-free ${ }^{a}$ & $0.158(0.353)$ & $0.159(0.211)$ & $0.168(0.223)$ & $0.255(0.336)$ & $0.222(0.465)$ \\
\hline$N$. of non-hydrogen atoms & 2135 & 2108 & 2104 & 1879 & 1871 \\
\hline macromolecules & 1814 & 1774 & 1804 & 1763 & 1757 \\
\hline ligands & 99 & 103 & 105 & 112 & 84 \\
\hline solvent & 222 & 231 & 195 & 4 & 30 \\
\hline protein residues & 227 & 224 & 225 & 228 & 227 \\
\hline RMS (bonds) (§) & 0.021 & 0.020 & 0.018 & 0.017 & 0.016 \\
\hline RMS (angles) (deg) & 2.20 & 2.05 & 2.09 & 2.08 & 1.96 \\
\hline Ramachandran-favored (\%) & 97.8 & 97.7 & 97.7 & 96.9 & 96.8 \\
\hline Ramachandran-allowed (\%) & 2.2 & 2.2 & 2.2 & 2.6 & 3.1 \\
\hline Ramachandran outliers (\%) & 0.00 & 0.00 & 0.00 & 0.44 & 0.00 \\
\hline average $B$-factor & 19.46 & 22.65 & 26.68 & 64.17 & 55.35 \\
\hline macromolecules & 18.02 & 21.11 & 25.16 & 62.95 & 55.26 \\
\hline ligands & 24.05 & 27.55 & 38.96 & 84.03 & 59.56 \\
\hline solvent & 29.12 & 32.25 & 34.14 & 45.07 & 48.34 \\
\hline
\end{tabular}

${ }^{a}$ Values in parentheses are for reflections in the highest resolution shell. ${ }^{b} R_{\text {merge }}=\sum\left|I_{\mathrm{i}}-\langle I\rangle\right| / \sum I_{i}$, where $I_{i}$ is the intensity of the $i$ th observation and $\langle I\rangle$ is the mean intensity of the reflection. ${ }^{c}$ The resolution cutoff was set to $\mathrm{CC}_{1 / 2}>0.3$, where $\mathrm{CC}_{1 / 2}$ is the Pearson correlation coefficient of two "half" data sets, each derived by averaging half of the observations for a given reflection.
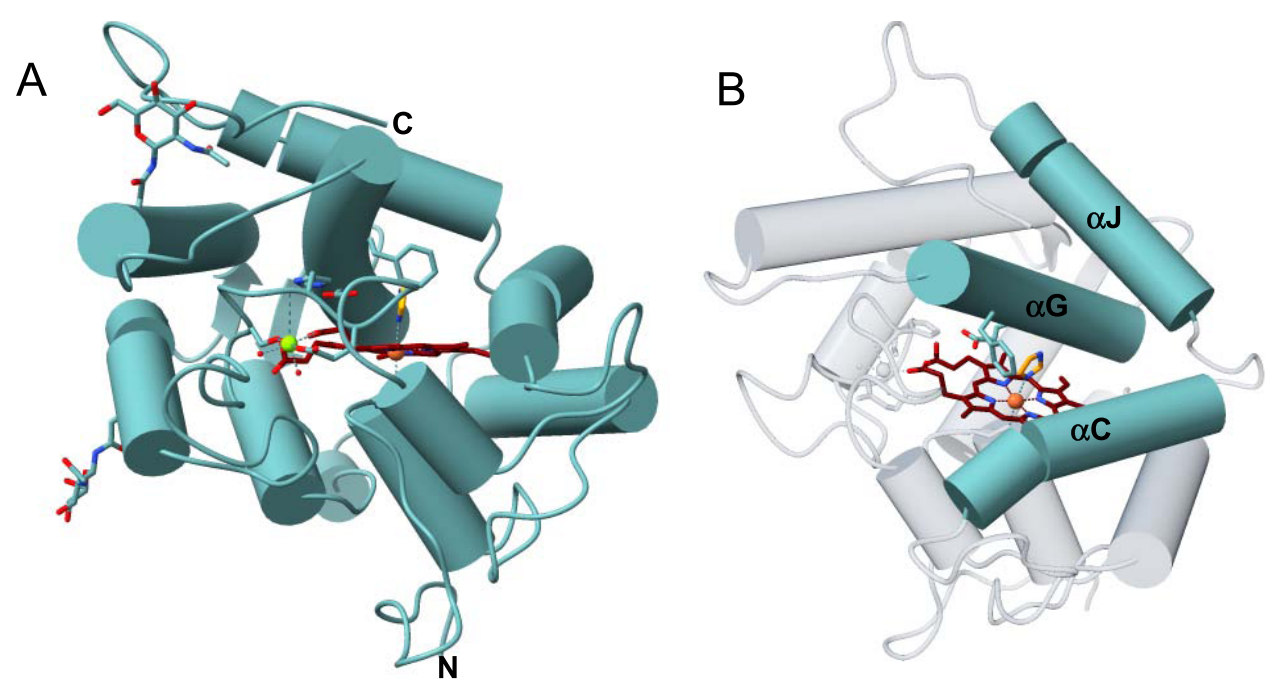

Figure 4. Crystal structure of HspUPO in complex with imidazole. (A) Ribbon diagram of the overall conformation of HspUPO. Protein, heme carbon atoms, magnesium ion, and imidazole are colored, respectively, in cyan, maroon, lawn green, and orange. " $\mathrm{N}$ " and " $\mathrm{C}$ " outline the $\mathrm{N}$ - and $\mathrm{C}$-termini, respectively. The C-terminal residues 251-261 are disordered. (B) The $\alpha$-helices $\alpha \mathrm{C}, \alpha \mathrm{G}$, and $\alpha$ J shape the active site.

Recombinant HspUPO is a highly glycosylated protein with a sugar contribution of $28 \mathrm{kDa}$ to the final molecular weight of 55 $\mathrm{kDa}(27 \mathrm{kDa}$ for the fully deglycosylated isoform). In light of this feature, it was of interest to understand if and how the glycosylations influence the enzyme properties. The enzymatically generated deglycosylated HspUPO showed steady-state kinetic parameters practically identical to those measured with the native fully glycosylated enzyme (Figures 1 and S1). However, deglycosylation clearly proved to negatively impact the resistance of the enzyme to thermal inactivation (Figure 3B). It is interesting to observe that deglycosylation had virtually no effect on the temperature of unfolding $\left(T_{\mathrm{m}}\right.$ of $76{ }^{\circ} \mathrm{C}$ for both the 


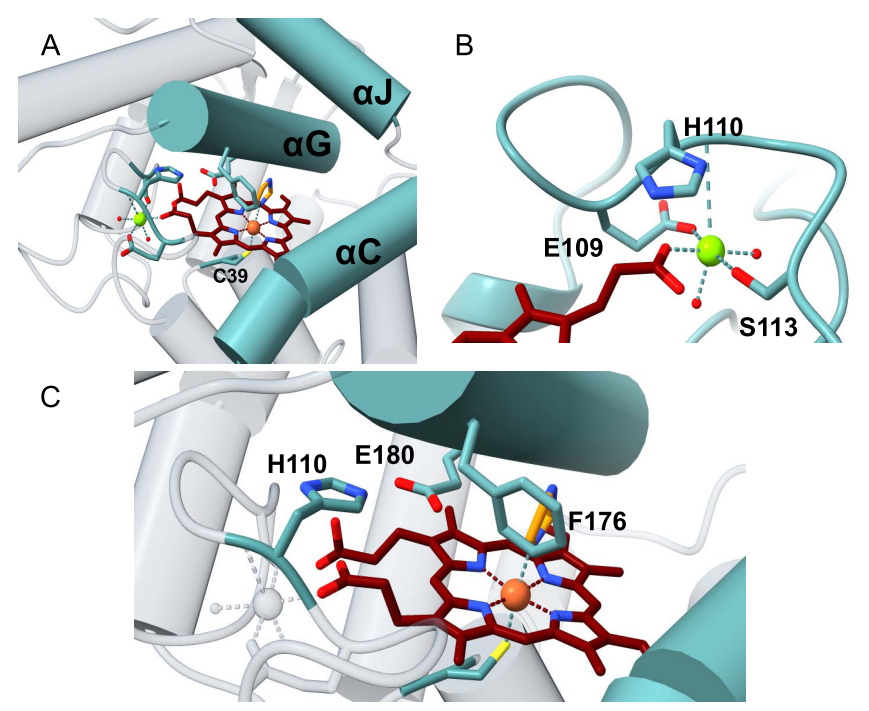

Figure 5. Close-up view of the HspUPO active site. (A) The substratebinding site is located at the bottom of a tunnel, lined by helices $\alpha \mathrm{J}, \alpha \mathrm{G}$, and $\alpha \mathrm{C}$. (B) A heme propionate group interacts with a magnesium ion that is coordinated by other three residues and two water molecules. (C) His110, Glu180, and Phe176 protrude from a loop and the $\alpha$-helix $\mathrm{G}$ and are positioned above the iron, providing critical elements for catalysis and substrate binding.

native and deglycosylated enzymes). Thus, the protective and stabilizing role of glycosylation becomes manifested only upon long incubations and by probing the enzymatic activities rather than protein denaturation. Activities may sense multiple factors, such as the loss of the heme, and not only the global protein unfolding as interrogated by the thermal denaturation methods. In essence, protein glycosylations contribute to the operational robustness of the enzyme.

Biotransformations. To characterize the reaction potential of HspUPO, various substrates displaying a broad scope of functional groups were investigated under the optimal conditions as suggested by the above-described experiments (Table 3 and Supporting Information). Ethylbenzene 1a, a common test substrate for hydroxylation, was regioselectively $\mathrm{C}-\mathrm{H}$ oxidized at the benzylic position to give the corresponding $(R)$-alcohol $(R)$-1b with $23 \%$ ee (Entry 1 in Table 3$)$. In this reaction also, the corresponding ketone, acetophenone 1c, was detected, indicating that $H s p$ UPO also has the potential to perform the oxidation of benzylic sec-alcohols. Indeed, when testing racemic phenylethanol $\mathrm{rac}-\mathbf{1} \mathbf{b}$, the alcohol was oxidized with high efficiency, giving exclusively the ketone product 1c with $>99 \%$ conversion (entry 2 ). The oxidation of 1a was also performed on a semipreparative scale $(20 \mathrm{~mL})$ with increased substrate concentration ( $100 \mathrm{mM})$, yielding $210 \mathrm{mg}$ of $1 \mathrm{c}(88 \%$ isolated yield, 92\% GC-yield, TON = 13 143). Thus, HspUPO transforms both phenylethanol enantiomers efficiently. This is worth noting since the well-characterized $A$. aegerita UPO converts ethylbenzene to the secondary benzyl alcohols (ee values up to $99 \%$ and TON $=10600$ ) with only traces of $\alpha$ ketones. $^{48,49}$ The reactivity of HspUPO toward phenylethanol can be very attractive because biocatalysts oxidizing both enantiomers of a sec-alcohol are highly desired, e.g., in the amination of sec-alcohols. In various studies, two stereocomplementary enzymes (mostly alcohol dehydrogenases) had to be employed to ensure the oxidation of both enantiomers; ${ }^{50-52}$ therefore, here, HspUPO may offer an alternative.
The benzylic primary alcohol 2a (veratryl alcohol) was oxidized to the corresponding carboxylic acid $2 \mathrm{c}$ as the main product, whereby at the conditions employed, significant amounts of aldehyde were also present (entry 3 ). The structures of minor side products formed were not elucidated. However, the masses indicate most likely demethylation of the substrate and dimerization. The ability of HspUPO to convert veratryl alcohol to the corresponding acid marks another substantial difference with $A$. aegerita UPO that mostly produces the aldehyde. $^{48,49}$

Turning to alkenes, cyclohexene 3a underwent epoxidation as the main reaction, giving cyclohexene oxide $3 \mathbf{b}$ as the dominant product in the product mixture (69\%, entry 4$)$. Additional products like the epoxy ketone $3 \mathrm{~d}$ indicate that first $\mathrm{C}-\mathrm{H}$ oxidation in the allylic position must have occurred prior to further oxidation. The oxidation of styrene $\mathbf{4 a}$ went to completion, leading to the corresponding $(S)$-epoxide $(S)-\mathbf{4 b}$ $(10 \%$ ee) as the main product $(91 \%$, entry 5$)$. These numbers favorably compare with $A$. aegerita UPO, which was reported to convert up to $71 \%$ styrene, giving the epoxide with an ee of $7 \%$ and TON of $7900 .^{48,49}$ Introducing a chloro-substituent in the para-position of styrene (substrate $\mathbf{5 a}$ ) resulted in a switch of the enantiomer formed in excess by HspUPO, thus giving the $(R)$ epoxide with moderate ee (30\%, entry 6$)$.

Indole $6 \mathbf{a}$ can be considered as a substrate with high potential for application since it is a precursor to indigo. HspUPO oxidized $6 \mathbf{a}$ to indigo $\mathbf{6 b}$ within only $1 \mathrm{~h}$ of incubation and conversions ranging from 75 to $96 \%$ (entry 7 ). The synthesis of $\mathbf{6 b}$ was also performed on a $20 \mathrm{~mL}$ scale with increased substrate concentration $(20 \mathrm{mM})$, yielding $51 \mathrm{mg}$ of the isolated product $(98 \%$, TON $=2813)$. A comparison with other reports ${ }^{53}$ using unspecific peroxygenases shows that HspUPO is a very promising biocatalyst for indigo production. For instance, the enzymatic preparation of indigo has been described in two patents, ${ }^{54,55}$ whereby an unspecific peroxygenase from Humicola insolens was able to give $72.4 \%$ indigo formation based on limiting cosubstrate $\mathrm{H}_{2} \mathrm{O}_{2}(2 \mathrm{mM})$ in a $100 \mathrm{~mL}$ reaction. $H s p$ UPO surpasses $H$. insolens UPO in terms of absolute indigo product concentration while also displaying a lower byproduct formation. Nevertheless, it should be stated that the varying reaction setups and conditions make it difficult to reliably compare the productivity of these biocatalysts toward indigo production.

In summary, this first tapping of the potential of the catalyst clearly indicates that HspUPO can catalyze various reactions such as hydroxylation in the benzylic position, alcohol oxidation, and epoxidation with high efficiency. Side reactions indicate also the potential for hydroxylation in the allylic position as well as demethylation.

Three-Dimensional Structure of HspUPO. Knowledge of the three-dimensional structure became of interest to gain further insights into the substrate and reactivity profiles featured by $H s p$ UPO. Glycosylated proteins may be problematic for crystallization, and HspUPO was no exception as no crystals were obtained with the native enzyme. The hurdle was overcome by crystallizing the deglycosylated protein, which we found to be enzymatically active and sufficiently stable for biochemical analysis. Indeed, deglycosylated HspUPO (Figure S1) readily crystallized, enabling the structure determination of several ligand complexes of the heme-bound holoenzyme. All of the crystal structures were solved at high resolutions ranging from $1.3 \AA$ to $2.5 \AA$ (Table 4). 
A

C
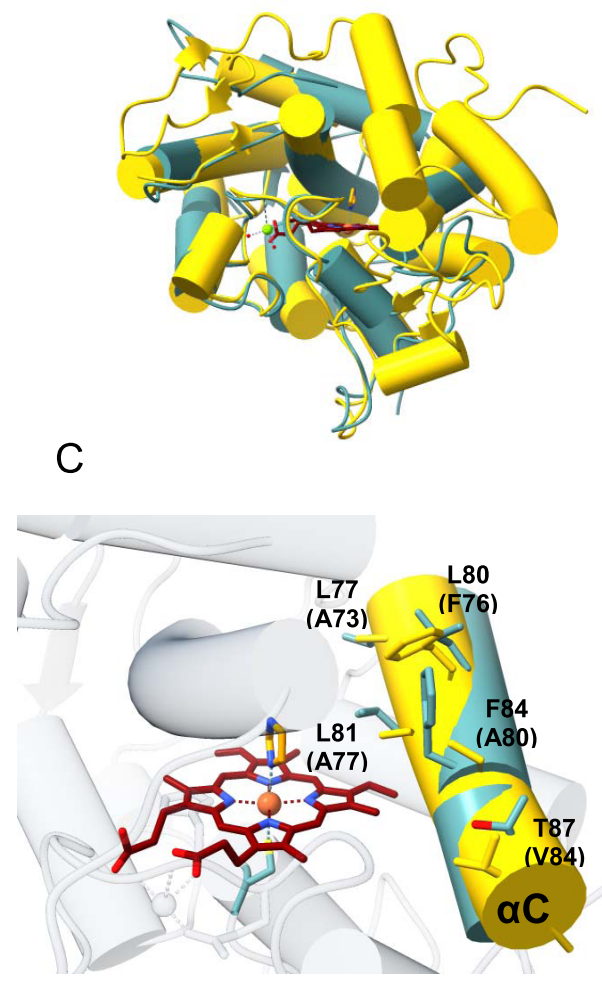

B

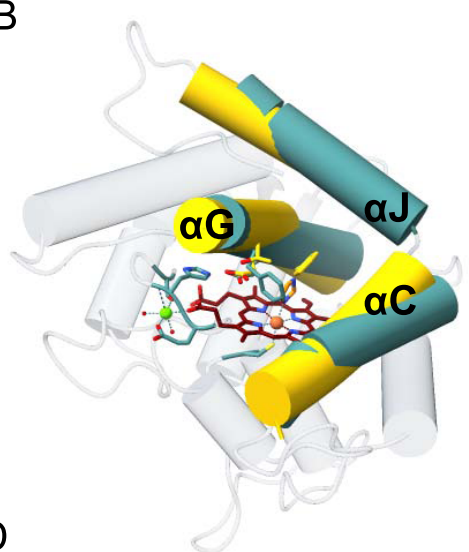

$E$

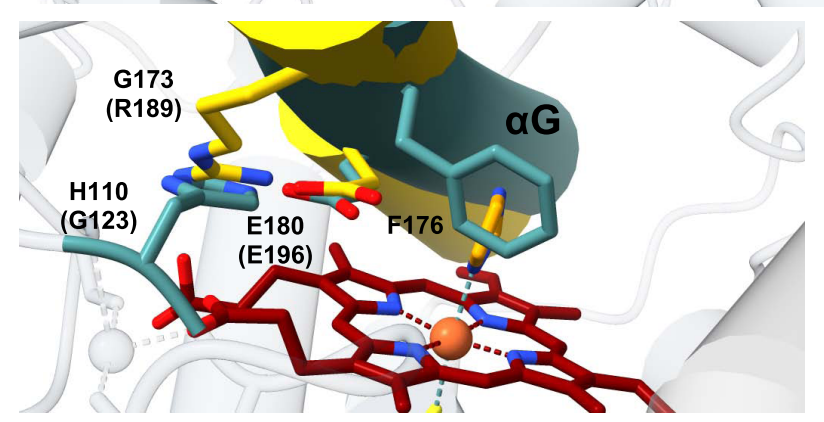

Figure 6. Structural comparisons. (A) Pairwise superposition between HspUPO and UPO from A. aegerita (PDB ID: 2YOR), colored in cyan and yellow, respectively. The A. aegerita enzyme has a 70-residue extension that comprises three helices not present in $H s p \mathrm{UPO}$. (B-E) The active sites of the two proteins differ due to reorientations of the helices $\alpha \mathrm{C}, \alpha \mathrm{G}$, and $\alpha \mathrm{J}(\mathrm{B})$, coupled to various changes in the side chains that protrude from these helices. The amino acid labels of $A$. aegerita UPO are in brackets.

Overall, HspUPO can be described as a highly ordered and compact protein, whose many helices completely wrap the heme prosthetic group. In agreement with size-exclusion chromatography data (Figure S1), the analysis of the crystal packing indicates that the protein is monomeric. The HspUPO threedimensional structure comprises $10 \alpha$-helices and two short $\beta$ strands, which we labeled following the current literature $(\alpha \mathrm{A}$ : $40-48 ; \alpha \mathrm{B}: 60-71 ; \alpha \mathrm{C}: 75-88 ; \alpha \mathrm{D}: 99-103 ; \alpha \mathrm{E}: 129-138$; $\alpha \mathrm{F}: 146-163 ; \alpha \mathrm{G}: 171-188 ; \alpha \mathrm{H}: 198-207 ; \alpha \mathrm{I}: 212-214 ; \beta 1$ : $143-145 ; \beta 2$ : $195-197) .{ }^{25}$ Two molecules of $N$-acetylglucosamine were found to be linked to Asn133 and Asn161 (Figure $4 A, B)$. The N-terminal residues $1-24$ form the signal peptide and were predicted to be cleaved during the protein maturation process. Indeed, the first ordered amino acid is Ser25. A noticeable feature is the high degree of order displayed by the protein structure as a whole. All protein residues display clearly defined electron density. Only the C-terminal residues, spanning from 251 to 261 , do not reveal any electron density owing to their flexible conformation.
The active site is a tube-shaped closed tunnel and is finely circumscribed by three $\alpha$-helices $(\alpha \mathrm{C}, \alpha \mathrm{G}, \alpha \mathrm{J})$ (Figures 4B and $5 \mathrm{~A})$. The iron atom of the heme sits at the dead-end of the tunnel. The prosthetic group is coordinated by the thiol side chain of Cys39, the axial ligand, and is firmly anchored to the protein through extensive interactions. A heme propionate group is bound to magnesium, which is further coordinated by two side chains (Glu109 and Ser113), a backbone nitrogen (His110), and two water molecules, defining an octahedral coordination sphere (Figure 5B).

Further active site analysis portrays three core side chains, His110, Glu180, and Phe176 above the Fe center (Figure 5C). Phe 176 provides a steric block that coordinates and channels the substrate toward the iron atom of the heme, whereas the His110Glu180 pair has been proposed to play a leading role in the catalytic cycle by promoting compound I formation (Scheme 1).

Based on sequence similarities, HspUPO belongs to the class I-so-called "short"-peroxygenases. ${ }^{56}$ Comparison of HspUPO with the structure of UPO from A. aegerita, ${ }^{25}$ a class II (long) 
A

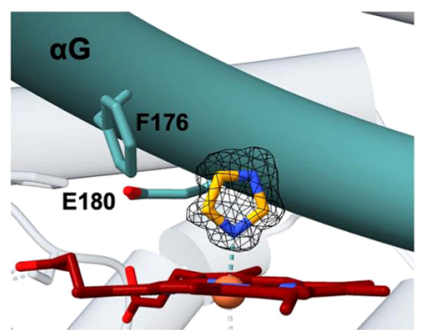

B

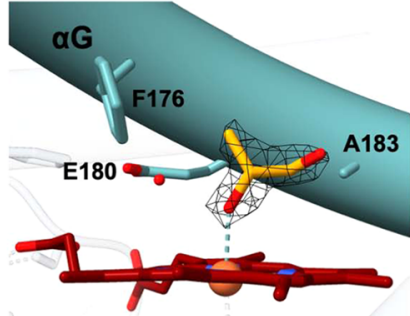

C
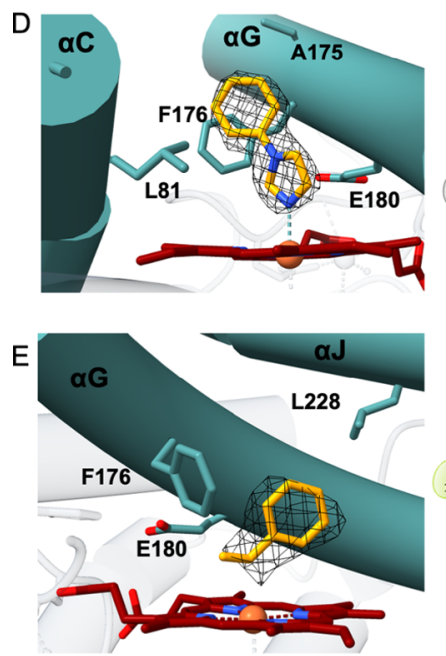

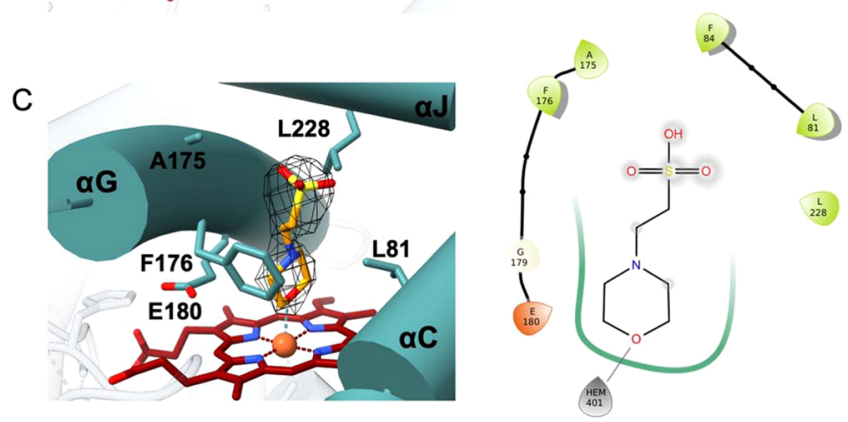

$\underset{\substack{\text { PHE } \\ 116}}{170}$
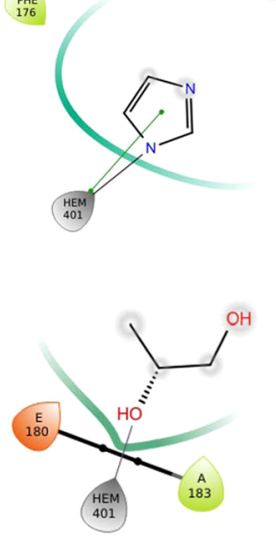

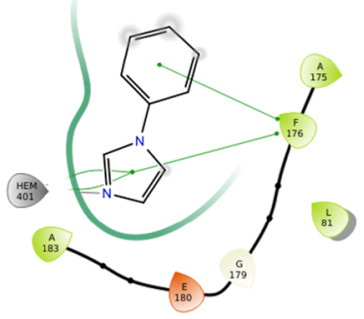

Figure 7. HspUPO active site in complex with (A) imidazole, (B) S-1,2propanediol, (C) MES, (D) 1-phenylimidazole, and (E) styrene. Left panels: weighted $2 F_{\mathrm{o}}-F_{\mathrm{c}}$ electron density contoured at $1.4 \sigma$. Right panels: two-dimensional schematic diagram of the interactions between ligands and the protein residues. Green lines indicate van der Waals contacts, whereas gray lines indicate metal coordination.

peroxygenase, shows that the two enzymes share a similar overall structure, with a root-mean-square deviation of $2.1 \AA$ for $201 \mathrm{C} \alpha$ atoms (Figure 6A).

However, the comparison also reveals a few evident differences. The long (class II) A. aegerita UPO features a 70residue $\alpha$-helical $\mathrm{C}$-terminal extension and a less compact structure compared to that of the short (class I) HspUPO. Moreover, the active-site shaping helices $\alpha \mathrm{C}, \alpha \mathrm{G}$, and $\alpha \mathrm{J}$ of HspUPO are shifted by about $3-4 \AA$ and reoriented by $\sim 10^{\circ}$ (Figure 6B). This rearrangement is coupled to several amino acid replacements, particularly on $\alpha \mathrm{C}$ and $\alpha \mathrm{G}$. Although the hydrophobic nature of these amino acids is mostly conserved, the bulkiness of their side chains is not, as detailed in Figure 6C,D. This results in a generally narrower substrate-binding site in HspUPO. Another cluster of critical variations is found in the residues that directly surround the iron center above the heme. The catalytic acid-base pair (Arg189-Glu196) of A. aegerita UPO is replaced by Gly173 and Glu180 in HspUPO, whereas Gly123 of A. aegerita UPO is replaced by His110 in HspUPO (Figure 6E). As a result of these amino acid replacements, the His110 side chain of HspUPO spatially overlaps on the Arg189 side chain of the $A$. aegerita structure. This observation validates the prediction that in the short (class I) UPOs, the catalytic role of "charge stabilizer" is played by a class I-specific conserved histidine (His110 in HspUPO) rather than by an arginine, as found for the class II enzymes (Arg189 in A. aegerita UPO).$^{20}$ In summary, besides an identical fold and similar overall conformations, the two peroxygenases differ in the fine details of the active site, and these differences can have far-reaching implications in the modulation of their substrate scopes. The narrow shape of the HspUPO site may well explain its preferences for aromatic substrates with small substituents, as evidenced by our bioconversion experiments (Table 3 ).

Different Ligands and Same Protein Conformation. The main aim of the structural analysis was to rationalize the substrate profile exhibited by HspUPO. Toward this aim, it was very helpful that crystals of deglycosylated $H s p$ UPO were found in many conditions and could be successfully used for data collection experiments. Inspection of the resulting electron densities revealed that various ligands were bound in proximity to the iron. Remarkably, the bulkiness and polarities of these ligands differ substantially, ranging from a small alcohol $[(S)$ 1,2-propanediol] to a small heterocycle (imidazole) to a larger molecule [MES; 2-(N-morpholino)ethanesulfonic acid]. In the crystal structure of the imidazole complex (Figure 7A), a ligand nitrogen directly coordinates the heme iron. Similarly, $(S)-1,2-$ propanediol and MES bind to the heme through their hydroxyl and ether oxygens, respectively (Figure $7 \mathrm{~B}, \mathrm{C}$ ). In light of the preference for aromatic substrates exhibited by HspUPO, we then decided to further investigate the ligand acceptance by considering aromatic ligands. We first took advantage of the propensity of heme to bind imidazole by conducting a soaking experiment with 1-phenylimidazole (Figure 7D), a double-ring imidazole-substituted molecule. As with imidazole, 1-phenylimidazole was found to coordinate the iron center with its nitrogen. Moreover, its aromatic substituent interacts with Phe176 through an edge-to-face interaction whereby the two aromatic rings are oriented orthogonal to each other. We next solved the structure of the enzyme bound to styrene, possibly the most efficiently converted substrate (Table 3 and Figure 6E). Also in this case, the ligand sits on top of the heme with its ethyl side chain oriented toward the iron and the edge of its aromatic ring facing the edge of the Phe 176 side chain. This binding mode is similar to that previously found in $A$. aegerita $\mathrm{UPO}^{25}$ and is fully compatible with catalysis leading to epoxidation styrene.

This set of enzyme-ligand structures corroborates the biotransformation experiments. All ligands are located in the same region at the bottom of the funnel-shaped tunnel leading to the heme in direct contact with the iron. The ligand-protein contacts comprise extensive van der Waals interactions involving the side chains that decorate the innermost segment of the tunnel. As shown by the 1,2-propanediol complex, HspUPO is able to bind alcohols as the hydroxyl group can orient itself 


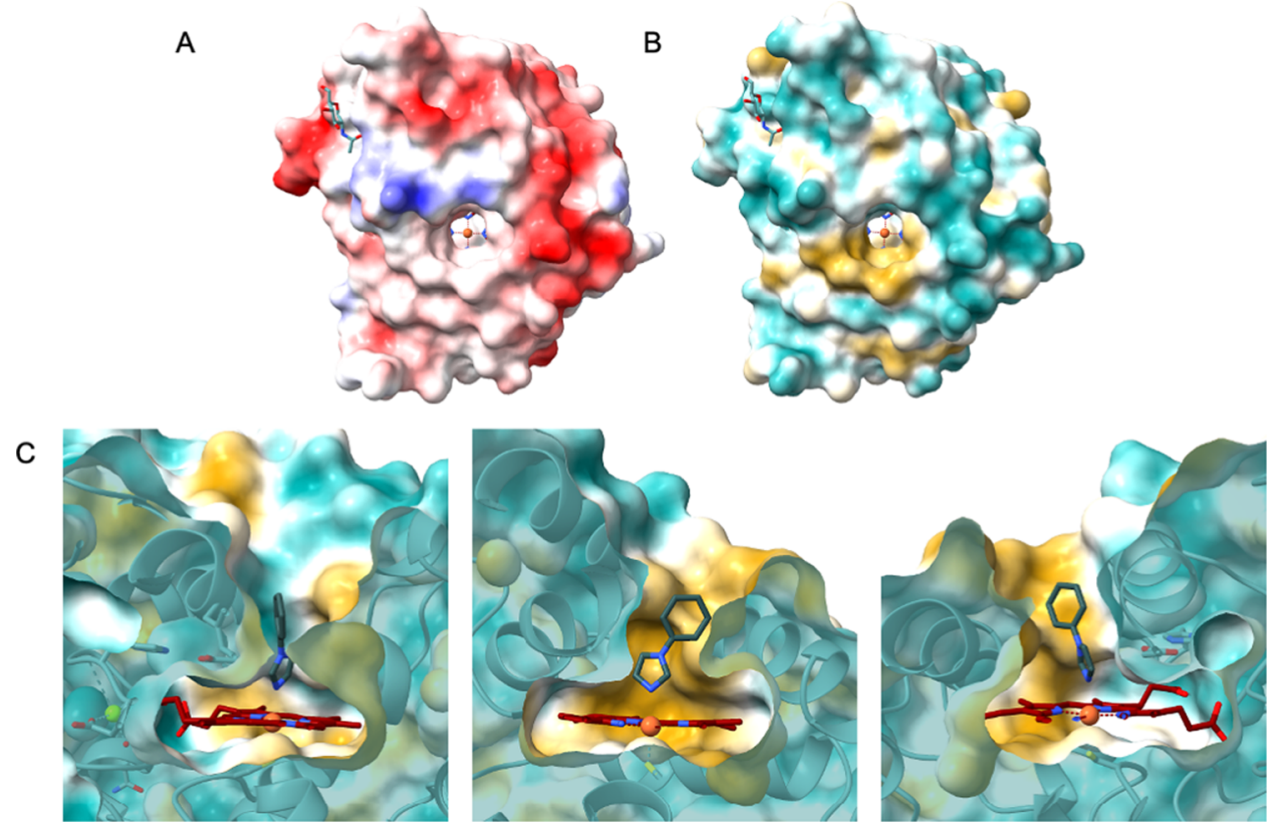

Figure 8. HspUPO molecular surfaces. (A) Enzyme surface colored by electrostatic potential as calculated with Coulombic surface coloring in Chimera. Blue and red indicate, respectively, positively and negatively charged residues. (B) Enzyme surface colored by the molecular lipophilicity potential, where cyan denotes hydrophilic residues and gold denotes hydrophobic ones. Image (C) shows close-up sliced views of the tunnel that brings to the active site cavity. The heme and 1-phenylimidazole arecolored in maroon and dark gray, respectively.

toward the iron (Figure 7B). This is in line with the capacity of oxidizing several prim- and sec-alcohols (entries 2 and 3 of Table 3). The structure with MES reveals how a cyclic aliphatic compound can bind in the active site, providing a clue about the binding of a substrate such as cyclohexene, which is efficiently oxidized by HspUPO (entry 4 of Table 3 ). The binding of 1phenylimidazole rationalizes the efficiency in indole conversion exhibited by HspUPO, as the two compounds have a similar steric hindrance and comprise a heterocyclic ring. Together with the 1-phenylimidazole complex, the structure with styrene shows how an aromatic ring can snugly fit at the bottom of the tunnel to establish several van der Waals interactions with the surrounding residues. A noticeable feature arising from these structural studies is that the binding of this rather diverse panel of ligands does not cause any conformational change in the active site. The only detectable variation is a slight, $0.1 \AA$, shift of the Phe176 side chain upon binding of 1-phenylimidazole. Moreover, none of the ligands forms hydrogen-bond interactions with the surrounding protein groups, as inspected with MAESTRO $^{57}$ (Figure 7). In the absence of highly specific interactions, the bound substrates are unlikely to be anchored in a tightly restrained single orientation. This feature may explain the low stereo- and enantioselectivities of the reactions, as outlined by the conversions of alcohol and styrene compounds, respectively (entries 2, 5, and 6 of Table 3). Along these lines, it is interesting to notice that the surface of the tunnel has a double-face nature, which can be appreciated by looking at Figure 8. Along the entire $12 \AA$ path, one side of the tunnel surface is mostly hydrophobic and populated by aromatic and aliphatic side chains, whereas the opposite side is more hydrophilic as it comprises hydrophilic side chains or main chain atoms (Figure 8C). Such a fine partition is evident also at the tunnel opening, where the side chains are arranged to form two hemi-circles. One is mostly hydrophobic, whereas the other is more hydrophilic, with a prevalence of positively charged groups (Figure 8A,B). With its bipartite nature and funnel shape, the active site of HspUPO seems perfectly tailored for dealing with substrates that are not exceedingly hydrophobic and bulky or require a precise constellation of hydrogen-bonding groups to enable their recognition.

\section{CONCLUSIONS}

The increasing interest in UPOs stems from their ability to operate using hydrogen peroxide only as the cosubstrate without the need for electron donors or auxiliary electron-transporting subunits. After an initial testing of six candidates, the UPO from Hypoxylon sp. EC38 was identified as a suitable enzyme. HspUPO can be expressed in high yields as a secreted recombinant protein using $P$. pastoris. In addition to the ease of expression and purification, HspUPO can withstand widely used organic solvents such as acetone and acetonitrile. Moreover, the enzyme can easily operate at a temperature of $35{ }^{\circ} \mathrm{C}$ although operational stability at high temperatures will probably need to be further improved. We further notice that HspUPO can sustain catalysis at relatively high $\mathrm{mM}$ concentrations of hydrogen peroxide. This is the critical feature that makes peroxygenases so attractive and distinguishes them from cytochrome P450s.

HspUPO is applicable for the transformation of various functional groups. Remarkably, HspUPO exhibits relatively low $K_{\mathrm{M}}$ values, in the double-digit $\mu \mathrm{M}$ range, and yet, we could not detect substrate inhibition in steady-state assays. These reactivities can be framed in the context of the three-dimensional structure. HspUPO displays a characteristic funnel-shaped tunnel that leads from the surface to the heme. The enzyme has a well-ordered overall structure, and this type of rigid and compact conformation finds a counterpart in the absence of detectable conformational changes upon binding of diverse ligands. No specific hydrogen-bonding interactions are found in any of the five enzyme-ligand complexes that have been crystallographically characterized. With a bipartite nature that provides hydrophobic and hydrophilic groups for interactions, 
the tunnel thereby functions as a molecular sieve, promoting the diffusion of small-to-medium-sized substrates that can reach to and react with the oxoferryl (compound I) intermediate (Scheme 1). Oxygenation is therefore afforded by promoting the encounter between the activated oxygen of the oxoferryl and the substrate in the highly confined environment at the end of the catalytic tunnel, which is in line with the low $K_{M}$ values. Such a combination of a rigid and structurally well-defined protein scaffold with an initial portfolio of known substrates highlights $H s p \mathrm{UPO}$ as a biocatalyst with high potential for the development of designer peroxygenases targeting specific substrates.

\section{ASSOCIATED CONTENT}

\section{s) Supporting Information}

The Supporting Information is available free of charge at https://pubs.acs.org/doi/10.1021/acscatal.1c03065.

Protein purification protocols, analytical methods, GC and HPLC traces (PDF)

\section{AUTHOR INFORMATION}

\section{Corresponding Authors}

Wolfgang Kroutil - Austrian Centre of Industrial Biotechnology, c/o Institute of Chemistry, University of Graz, $8010 \mathrm{Graz}$, Austria; Institute of Chemistry, University of Graz, NAWI Gaz, BioTechMed Graz, 8010 Graz, Austria; Field of Excellence BioHealth-University of Graz, 8010 Graz, Austria; ○ orcid.org/0000-0002-2151-6394;

Email: wolfgang.kroutil@uni-graz.at

Andrea Mattevi - Department of Biology and Biotechnology, University of Pavia, 27100 Pavia, Italy; 이이.org/00000002-9523-7128; Email: andrea.mattevi@unipv.it

\section{Authors}

Laura Rotilio - Department of Biology and Biotechnology, University of Pavia, 27100 Pavia, Italy

Alexander Swoboda - Austrian Centre of Industrial Biotechnology, c/o Institute of Chemistry, University of Graz, 8010 Graz, Austria

Katharina Ebner - Institute of Molecular Biotechnology, Graz University of Technology, 8010 Graz, Austria

Claudia Rinnofner - Institute of Molecular Biotechnology, Graz University of Technology, 8010 Graz, Austria

Anton Glieder - Institute of Molecular Biotechnology, Graz University of Technology, 8010 Graz, Austria

Complete contact information is available at: https://pubs.acs.org/10.1021/acscatal.1c03065

\section{Author Contributions}

L.R. performed all activity measurements, purifications, kinetics, and crystallographic studies. C.R. performed the cloning and initial expression and screening experiments. A.S. performed the biotransformations. K.E. carried out protein preparations. W.K., A.G., and A.M. designed and supervised the research. The manuscript was written with contributions from all authors.

\section{Funding}

This work was supported by the Federal Ministry of Science, Research and Economy (BMWFW), the Federal Ministry of Traffic, Innovation and Technology (bmvit), the Styrian Business Promotion Agency SFG, the Standortagentur Tirol, and the Government of Lower Austrian and Business Agency Vienna through the COMET-Funding Program managed by the Austrian Research Promotion Agency FFG. Funding from the
Italian Ministry of Education, University and Research (MIUR): Dipartimenti di Eccellenza Program (2018-2022)-Department of Biology and Biotechnology "L. Spallanzani” University of Pavia, is acknowledged.

\section{Notes}

The authors declare no competing financial interest.

\section{ABBREVIATIONS}

UPO, unspecific peroxygenase; HspUPO, Hypoxylon sp. UPO; ABTS, 2,2'-azino-bis(3-ethylbenzothiazoline-6-sulfonic acid) diammonium salt

\section{REFERENCES}

(1) Newhouse, T.; Baran, P. S. If C-H Bonds Could Talk: Selective C$\mathrm{H}$ Bond Oxidation. Angew. Chem., Int. Ed. 2011, 50, 3362-3374.

(2) Sheldon, R. A.; Norton, M. Green chemistry and the plastic pollution challenge: towards a circular economy. Green Chem. 2020, 6310-6322.

(3) Sheldon, R. A.; Woodley, J. M. Role of Biocatalysis in Sustainable Chemistry. Chem. Rev. 2018, 118, 801-838.

(4) Clomburg, J. M.; Crumbley, A. M.; Gonzalez, R. Industrial biomanufacturing: The future of chemical production. Science 2017, 355, No. aag0804.

(5) Li, Z.; van Beilen, J. B.; Duetz, W. A.; Schmid, A.; de Raadt, A.; Griengl, H.; Witholt, B. Oxidative biotransformations using oxygenases. Curr. Opin. Chem. Biol. 2002, 6, 136-144.

(6) de Montellano, P. R. O. Hydrocarbon Hydroxylation by Cytochrome P450 Enzymes. Chem. Rev. 2009, 110, 932-948.

(7) Krest, C. M.; Onderko, E. L.; Yosca, T. H.; Calixto, J. C.; Karp, R. F.; Livada, J.; Rittle, J.; Green, M. T. Reactive Intermediates in Cytochrome P450 Catalysis. J. Biol. Chem. 2013, 288, 17074-17081.

(8) Smith, G. C. M.; Tew, D. G.; Wolf, R. Dissection of NADPHcytochrome $\mathrm{P} 450$ oxidoreductase into distinct functional domains. Proc. Natl. Acad. Sci. U.S.A. 1994, 91, 8710-8714.

(9) Holtmann, D.; Hollmann, F. The Oxygen Dilemma: A Severe Challenge for the Application of Monooxygenases? ChemBioChem 2016, 17, 1391-1398.

(10) Holtmann, D.; Fraaije, M. W.; Arends, I. W.; Opperman, D. J.; Hollmann, F. The taming of oxygen: biocatalytic oxyfunctionalisations. Chem. Commun. 2014, 50, 13180-13200.

(11) Park, H.; Park, G.; Jeon, W.; Ahn, J. O.; Yang, Y. H.; Choi, K. Y. Whole-cell biocatalysis using cytochrome $\mathrm{P} 450$ monooxygenases for biotransformation of sustainable bioresources (fatty acids, fatty alkanes, and aromatic amino acids). Biotechnol. Adv. 2020, 40, 107504.

(12) Hollmann, F.; Arends, I. W. C. E.; Buehler, K. Biocatalytic Redox Reactions for Organic Synthesis: Nonconventional Regeneration Methods. Chem CatChem 2010, 2, 762-782.

(13) Mifsud, M.; Gargiulo, S.; Iborra, S.; Arends, I. W. C. E.; Hollmann, F.; Corma, A. Photobiocatalytic chemistry of oxidoreductases using water as the electron donor. Nat. Commun. 2014, 5, No. 3145 .

(14) Fujishiro, T.; Shoji, O.; Nagano, S.; Sugimoto, H.; Shiro, Y.; Watanabe, Y. Crystal Structure of H2O2-dependent Cytochrome P450SP $\alpha$ with Its Bound Fatty Acid Substrate: insight into the regioselective hydroxylation of fatty acids at the $\alpha$ position. J. Biol. Chem. 2011, 286, 29941-29950.

(15) Girvan, H. M.; Poddar, H.; McLean, K. J.; Nelson, D. R.; Hollywood, K. A.; Levy, C. W.; Leys, D.; Munro, A. W. Structural and catalytic properties of the peroxygenase $\mathrm{P} 450$ enzyme CYP152K6 from Bacillus methanolicus. J. Inorg. Biochem. 2018, 188, 18-28.

(16) Pickl, M.; Kurakin, S.; Cantù Reinhard, F. G.; Schmid, P.; Pöcheim, A.; Winkler, C. K.; Kroutil, W.; de Visser, S. P.; Faber, K. Mechanistic Studies of Fatty Acid Activation by CYP152 Peroxygenases Reveal Unexpected Desaturase Activity. ACS Catal. 2019, 9, 565-577. 
(17) Yu, D.; Wang, J.-B.; Reetz, M. T. Exploiting Designed OxidasePeroxygenase Mutual Benefit System for Asymmetric Cascade Reactions. J. Am. Chem. Soc. 2019, 141, 5655-5658.

(18) Dunham, N. P.; Arnold, F. H. Nature's Machinery, Repurposed: Expanding the Repertoire of Iron-Dependent Oxygenases. ACS Catal. 2020, 10, 12239-12255.

(19) Ullrich, R.; Nüske, J.; Scheibner, K.; Spantzel, J.; Hofrichter, M. Novel Haloperoxidase from the Agaric Basidiomycete Agrocybe aegerita Oxidizes Aryl Alcohols and Aldehydes. Appl. Envirom. Microbiol. 2004, $70,4575-4581$.

(20) Hofrichter, M.; Kellner, H.; Pecyna, M. J.; Ullrich, R. Fungal unspecific peroxygenases: heme-thiolate proteins that combine peroxidase and cytochrome p450 properties. Adv. Exp. Med. Biol. 2015, 851, 341-368.

(21) Püllmann, P.; Knorrscheidt, A.; Munch, J.; Palme, P. R.; Hoehenwarter, W.; Marillonnet, S.; Alcalde, M.; Westermann, B.; Weissenborn, M. J. A modular two yeast species secretion system for the production and preparative application of unspecific peroxygenases. Commun. Biol. 2021, 4, No. 562.

(22) Gomez de Santos, P.; Cervantes, F. V.; Tieves, F.; Plou, F. J.; Hollmann, F.; Alcalde, M. Benchmarking of laboratory evolved unspecific peroxygenases for the synthesis of human drug metabolites. Tetrahedron 2019, 75, 1827-1831.

(23) Wang, Y.; Lan, D.; Durrani, R.; Hollmann, F. Peroxygenases en route to becoming dream catalysts. What are the opportunities and challenges? Curr. Opin. Chem. Biol. 2017, 37, 1-9.

(24) Shoji, O.; Watanabe, Y. Peroxygenase reactions catalyzed by cytochromes P450. J. Biol. Inorg. Chem. 2014, 19, 529-539.

(25) Piontek, K.; Strittmatter, E.; Ullrich, R.; Gröbe, G.; Pecyna, M. J.; Kluge, M.; Scheibner, K.; Hofrichter, M.; Plattner, D. A. Structural Basis of Substrate Conversion in a New Aromatic Peroxygenase: Cytochrome P450 functionality with benefits. J. Biol. Chem. 2013, 288, 34767-34776.

(26) Ramirez-Escudero, M.; Molina-Espeja, P.; Gomez de Santos, P.; Hofrichter, M.; Sanz-Aparicio, J.; Alcalde, M. Structural Insights into the Substrate Promiscuity of a Laboratory-Evolved Peroxygenase. ACS Chem. Biol. 2018, 13, 3259-3268.

(27) Bordeaux, M.; Galarneau, A.; Drone, J. Catalytic, Mild, and Selective Oxyfunctionalization of Linear Alkanes: Current Challenges. Angew. Chem., Int. Ed 2012, 51, 10712-10723.

(28) Gutiérrez, A.; Babot, E. D.; Ullrich, R.; Hofrichter, M.; Martìnez, A. T.; Del Rì, J. Regioselective oxygenation of fatty acids, fatty alcohols and other aliphatic compounds by a basidiomycete heme-thiolate peroxidase. Arch. Biochem. Biophys. 2011, 514, 33-43.

(29) Kluge, M.; Ullrich, R.; Dolge, C.; Scheibner, K.; Hofrichter, M. Hydroxylation of naphthalene by aromatic peroxygenase from Agrocybe aegerita proceeds via oxygen transfer from $\mathrm{H} 2 \mathrm{O} 2$ and intermediary epoxidation. Appl. Microbiol. Biotechnol. 2009, 81, 1071-1076.

(30) Zhang, W.; Li, H.; Younes, H. H. S.; Gòmez de Santos, P.; Tieves, F.; Grogan, G.; Pabst, M.; Alcalde, M.; Whitwood, A. C.; Hollmann, F. Biocatalytic Aromaticity-Breaking Epoxidation of Naphthalene and Nucleophilic Ring-Opening Reactions. ACS Catal. 2021, 11, 26442649.

(31) Molina-Espeja, P.; Canellas, M.; Plou, F. J.; Hofrichter, M.; Lucas, F.; Guallar, V.; Alcalde, M. Synthesis of 1-Naphthol by a Natural Peroxygenase Engineered by Directed Evolution. ChemBioChem 2016, 17, 341-349.

(32) Karich, A.; Kluge, M.; Ullrich, R.; Hofrichter, M. Benzene oxygenation and oxidation by the peroxygenase of Agrocybe aegerita. $A M B$ Express 2013, 3, No. 5.

(33) Tonin, F.; Tieves, F.; Willot, S.; van Troost, A.; van Oosten, R.; Breestraat, S.; van Pelt, S.; Alcalde, M.; Hollmann, F. Pilot-Scale "Production of Peroxygenase from Agrocybe aegerita. Org Process Res Dev. 2021, 25, 1414-1418.

(34) Kluge, M.; Ullrich, R.; Scheibner, K.; Hofrichter, M. Stereoselective benzylic hydroxylation of alkylbenzenes and epoxidation of styrene derivatives catalyzed by the peroxygenase of Agrocybe aegerita. $A M B$ Express 2013, 14, No. 5.
(35) Molina-Espeja, P.; Garcia-Ruiz, E.; Gonzalez-Perez, D.; Ullrich, R.; Hofrichter, M.; Alcalde, M. Directed evolution of unspecific peroxygenase from Agrocybe aegerita. Appl. Environ. Microbiol. 2014, 80, 3496-3507.

(36) Molina-Espeja, P.; Ma, S.; Mate, D. M.; Ludwig, R.; Alcalde, M. Tandem-yeast expression system for engineering and producing unspecific peroxygenase. Enzyme Microb. Technol. 2015, 73-74, 2933.

(37) Püllmann, P.; Weissenborn, M. J. Improving the Heterologous Production of Fungal Peroxygenases through an Episomal Pichia pastoris Promoter and Signal Peptide Shuffling System. ACS Synth. Biol. 2021, 10, 1360-1372.

(38) Carro, J.; Gonzalez-Benjumea, A.; Fernandez-Fueyo, E.; Aranda, C.; Guallar, V.; Gutierrez, A.; Martinez, A. T. Modulating Fatty Acid Epoxidation vs Hydroxylation in a Fungal Peroxygenase. ACS Catal. 2019, 6234-6242.

(39) Linde, D.; Olmedo, A.; Gonzalez-Benjumea, A.; Estévez, M.; Renau-Minguez, C.; Carro, J.; Fernandez-Fueyo, E.; Gutierrez, A.; Martinez, A. T. Two New Unspecific Peroxygenases from Heterologous Expression of Fungal Genes in Escherichia coli. Appl. Environ. Microbiol. 2020, 86, No. e02899-19.

(40) Garrigós-Martínez, J.; Weninger, A.; Montesinos-Seguí, J. L.; Schmid, C.; Valero, F.; Rinnofner, C.; Glieder, A.; Garcia-Ortega, X. Scalable production and application of Pichia pastoris whole cell catalysts expressing human cytochrome P450 2C9. Microb. Cell Fact. 2021, 20, No. 90

(41) Kabsch, W. Integration, scaling, space-group assignment and post-refinement. Acta Crystallogr., Sect. D: Biol. Crystallogr. 2010, 66, 133-144.

(42) Winn, M. D.; Ballard, C. C.; Cowtan, K. D.; Dodson, E. J.; Emsley, P.; Evans, P. R.; Keegan, R. M.; Krissinel, E. B.; Leslie, A. G. W.; McCoy, A.; McNicholas, S. J.; Murshudov, G. N.; Pannu, N. S.; Potterton, E. A.; Powell, H. R.; Read, R. J.; Vagin, A.; Wilson, K. S. Overview of the CCP4 suite and current developments. Acta Crystallogr., Sect. D: Biol. Crystallogr. 2011, 67, 235-242.

(43) Vagin, A.; Teplyakov, A. MOLREP: an Automated Program for Molecular Replacement. Acta Crystallogr., Sect. D: Biol. Crystallogr. 1997, 30, 22-25.

(44) Murshudov, G. N.; Vagin, A.; Lebedev, A.; Wilson, K. S.; Dodson, E. J. Effcient anisotropic refnement of macromolecular structures using FFT. Acta Crystallogr., Sect. D: Biol. Crystallogr. 1999, $55,247-255$.

(45) Emsley, P.; Cowtan, K. Coot: model-building tools for molecular graphics. Acta Crystallogr., Sect. D: Biol. Crystallogr. 2004, 60, 21262132.

(46) Pettersen, E. F.; Goddard, T. D.; Huang, C. C.; Couch, G. S.; Greenblatt, D. M.; Meng, E. C.; Ferrin, T. E. UCSF Chimera-A visualization system for exploratory research and analysis. J. Comput. Chem. 2004, 25, 1605-1612.

(47) Holm, L. Benchmarking fold detection by DaliLite v.5. Bioinformatics 2019, 35, 5326-5327.

(48) Bormann, S.; Gomez-Baraibar, A.; Ni, Y.; Holtmann, D.; Hollmann, F. Specific oxyfunctionalisations catalysed by peroxygenases: opportunities, challenges and solutions. Catal. Sci. Technol 2015, 2038-2052.

(49) Kluge, M.; Ullrich, R.; Scheibner, K.; Hofrichter, M. Stereoselective benzylic hydroxylation of alkylbenzenes and epoxidation of styrene derivatives catalyzed by the peroxygenase of Agrocybe aegerita. Green Chem. 2012, 440-446.

(50) Wang, H.; Zheng, Y.-C.; Chen, F.-F.; Xu, J.-H.; Yu, H.-L. Enantioselective Bioamination of Aromatic Alkanes Using Ammonia: A Multienzymatic Cascade Approach. ChemCatChem 2020, 12, 20772082.

(51) Mutti, F. G.; Knaus, T.; Scrutton, N.; Breuer, M.; Turner, N. J. Conversion of alcohols to enantiopure amines through dual-enzyme hydrogen-borrowing cascades. Science 2015, 349, 1525-1529.

(52) Tian, K.; Li, Z. A Simple Biosystem for the High-Yielding Cascade Conversion of Racemic Alcohols to Enantiopure Amines. Angew. Chem., Int. Ed. 2020, 59, 21745-21751. 
(53) Fabara, A. N.; Fraaije, M. W. An overview of microbial indigoforming enzymes. Appl. Microbial. Biotechnol. 2020, 104, 925-933.

(54) Kalum, L.; Lund, H.; Hofrichter, M.; Ullrich, R. Enzymatic Preparation of Indigo Dyes and Intermediates. WO2014122109A12014.

(55) Tovborg, M.; Hofrichter, M.; Poraj-Kobielska, M.; Lund, H. Enzymatic Preparation of Indigo Dyes and In Situ Dyeing Process. WO2018002379A22017.

(56) Kellner, H.; Luis, P.; Pecyna, M. J.; Barbi, F.; Kapturska, D.; Kruger, D.; Zak, D. R.; Marmeisse, R.; Vadenbol, M.; Hofrichter, M. Widespread occurrence of expressed fungal secretory peroxidases in forest soils. PLoS One 2014, No. e95557.

(57) Bell, J. A.; Cao, Y.; Gunn, J. R.; Day, T.; Gallicchio, E.; Zhou, Z.; Levy, R.; Farid, R. PrimeX and the Schrödinger computational chemistry suite of programs. Int. Tables Crystallogr. 2012, 534-538. 